\title{
A Magnetic Design Method Considering DC- Biased Magnetization for Integrated Magnetic Components Used in Multi-Phase Boost Converters
}

\author{
Jun Imaoka, Member, IEEE, Kenkichiro Okamoto, Shota Kimura, Student Member, IEEE, \\ Mostafa Noah, Student Member, IEEE, Wilmar Martinez, Member, IEEE, Masayoshi Yamamoto, Member, IEEE, \\ Masahito Shoyama, Senior Member, IEEE
}

\begin{abstract}
High-power-density and high-efficiency in DC/DC converters are required in various applications such as the automotive application. Interleaved multi-phase circuits with integrated magnetic components can fulfill these requirements because passive components occupying significant space in power converters can be downsized without high-switching frequency driving of power devices. However, DC-biased magnetization is a drawback of integrated magnetic components because of unbalanced inductor average currents. This imbalance arises from the tolerance between the phase components. To overcome this problem, inductor average current control is implemented in interleaved multi-phase DC/DC converters. Nevertheless, the imbalance cannot be completely eliminated because the current sensors inserted into each phase have gain errors. The purpose of this paper is to present a magnetic design method to improve the immunity to unbalanced currents. A comprehensive analysis is carried out with two main objectives: 1) to prevent magnetic saturation, which may arise due to the current unbalance and 2) to downsize the magnetic components by selecting the optimal coupling coefficient taking into consideration the maximum permissible percentage of unbalanced currents. Simulation case studies are presented to support the analysis. Finally, a $1 \mathrm{~kW}$ prototype of the interleaved boost converter is built to validate the accuracy of the design method.
\end{abstract}

Index Terms - Boost converter, interleaved converter, multiphase, integrated magnetic components, DC-biased magnetization

Manuscript received October 24, 2016; revised March 29, 2017; accepted May 11, 2017. This work was partially supported by the Japan Society for the Promotion of Science (JSPS) KAKENHI Grant number 16K18059.

J. Imaoka, K. Okamoto and M. Shoyama are with the Department of Electrical Engineering, Kyushu University, 744 Motooka, Fukuoka, Japan (e-mail: imaoka@ees.kyushu-u.ac.jp; ie216662@ckt.ees.kyushuu.ac.jp; shoyama@ees.kyushu-u.ac.jp).

S. Kimura and M. Noah are with the Department of Mechanical, Electrical and Electronic engineering, Shimane University, 1060 Nishikawatsu, Matsue, Japan (e-mail: s159862@matsu.shimane-u.ac.jp; mosta.noah@gmail.com).

W. Martinez is with Toyota Technological Institute, 2-12-1 Hisakata, Tempaku-ku, Nagoya, Japan (e-mail: w.h.martinez@ieee.org)

M. Yamamoto is with Institute of Materials and Systems for Sustainability (IMaSS), Nagoya University, Furo-cho, Chikusa-ku, Nagoya, Japan (e-mail: m.yamamoto@imass.nagoya-u.ac.jp)

\section{INTRODUCTION}

Q FFORTS to achieve high-power-density and develop highefficiency DC/DC converters are essential to improve the portability of power conversion systems, and to conserve energy. In particular, the importance of power converters with their outstanding performance is growing along with the growth of the market in applications such as, eco-friendly automotive industries [1]-[5], low-voltage and large-current voltage regulators for Micro Computer Units [6]-[8], and renewable energies applications [9]-[10], among others. In addition, saving metal resources, including rare and base metals for magnetic components used in power converters, is a global concern [11]-[13].

Power converters are usually heavy and occupy significant space due to passive components such as inductors and capacitors that are used for energy storage. Therefore, downsizing of passive components is an effective way of achieving high power density for the entire converter. As a major solution method for downsizing passive components, high-switching frequency driving of power devices is a wellknown technique. However, the disadvantage of this technique is that it leads to additional problems such as increased EMI/RFI noise or concentric thermal stress in active/passive devices. Therefore, many-sided solutions for high power density are required [14].

Interleaved multi-phase circuit topologies have attracted attention as one of the solutions to fulfill these demands. In general, interleaved multi-phase converters are switched with a 360 degrees/PN (PN: number of phases) phase shift and the same duty ratio. The attractive features of interleaved multiphase converters are as follows

1) This topology can downsize the output/input smoothing capacitors in comparison with single-phase converters, because the capacitance value and the effective current value flowing through the capacitors can be reduced by the alternating power transfer [4], [15].

2) This approach allows the input current to be shared among the phases. Therefore, power losses and thermal stress per active/passive devices can be reduced or distributed. 
3) It is well-known from the literature that multi-phase topologies help to suppress electromagnetic interference (EMI) by increasing the number of phases in interleaved flyback converters [16]-[17] or by changing the phase shift degree in interleaved boost power factor correction converters [17]-[18].

The number of power devices and their drivers increases as a result of adapting multi-phase topologies. However, these devices can be packaged into multi-chip modules or intelligent power modules to reduce their mounting space, parasitic inductance, and resistance.

On the other hand, the number of magnetic components is similar to the number of parallel phases. Therefore, integrated magnetic components are used, whereby multiple windings can be installed on a single magnetic core. This integrated magnetic concept has been applied in both isolated and non-isolated DC/DC converters [3]-[5], [7]-[9], [19]-[22], [24]-[28]. The integrated magnetic components provide the following attractive features in interleaved multi-phase boost converters.

1) DC fluxes generated by inductor average currents can be effectively canceled by the inversely coupling property. In addition, the peak-to-peak amplitude of the AC flux in a part of the magnetic core can be reduced. As a result, the downsizing of magnetic components can be realized.

2) Owing to mutual induction, inductor current ripple in each phase can be reduced. Consequently, the use of a small energy storage inductance for each phase is allowed. This is in contrast with the case of their discrete magnetic counterparts.

3) From a control-theory perspective, integrated magnetics improve the transient response speed because the inductor current slew rate is higher than that for non-coupled inductors [22]-[24].

Therefore, the use of interleaved multi-phase circuit topology with integrated magnetic components results in outstanding performance for downsizing both the inductive and capacitive components.

Furthermore, in order to improve the performance of the integrated magnetic technique, magnetic core structures [5], [7]-[8], [25], applications of magnetic materials [3], winding arrangements [27]-[28], and the derivation method for equivalent circuit models [29] have been discussed in detail.

In fact, in practical applications, there is a tolerance between the inductor currents in each phase, because of the inductor winding's uneven parasitic resistances, and onresistances in the used power devices that are never exactly identical among the phases. In addition, a duty ratio difference between each switch may also affect the current imbalance. This current imbalance has two main negative outcomes: a) a bigger value of the input/output capacitance is needed to compensate for the unbalanced power transfer, and b) DCbiased magnetization occurs, which leads to a bigger magnetic core size to handle the undesirable flux.

One possible way of tackling the current imbalance in interleaved multi-phase boost converters is to employ inductor average current controls. These control methods usually require inserting one current sensor per phase. Thus, the total number of current sensors equals the number of phases. These current sensors are usually connected in series with the inductors in each phase. However, it is practically difficult to completely eliminate the current imbalance because gain errors are introduced by the current sensors due to a difference of linearity, DC offsets, hysteresis, and sensitivity properties of the current sensors. Therefore, expensive high-precision current sensors or trained labor to adjust the gain of the sensors are needed. Hence, the large-scale production of these converters is difficult.

In order to overcome the aforementioned problems, inductor current measurement methods using a single-current sensor, connected in series with the smoothing capacitor [30] or to the DC-link part [31]-[32], have been developed. The attractive features of these methods are that they not only reduce the current sensor's cost, volume and weight but also overcome the problem of gain mismatch between the current sensors. However, these methods also suffer from two disadvantages: first, the minimum and maximum duty cycles are limited [31], and second, setting the over-current protection becomes difficult because the inductor current cannot be measured directly. Therefore, considering the above features, setting the current sensors in all phases is also an attractive option. Consequently, handling the DC-biased magnetization becomes a challenge, especially during the occurrence of small unbalanced inductor currents [33]-[34].

This paper proposes a magnetic design method for integrated magnetic components considering the DC-biased magnetization when there are unbalanced inductor average currents. As a case study, this paper focuses on the two-phase interleaved boost converter with a loosely coupled inductor (LCI) using EE or EI core shape. The features of the novel design method and the contributions of this paper are as follows

1) With the purpose of improving the immunity to inductor average current unbalance, which may lead to magnetic saturation, the proposed method relies on inserting a small air gap in the transformer part of the LCI to increase the reluctance in order to minimize the effect of DC-biased magnetization.

2) However, inserting an air gap in the transformer part of the LCI will definitely decrease the value of the coupling coefficient. Consequently, lower coupling factors lead to a bigger magnetic core.

3) Based on (1) and (2), it is clear that there is a trade-off between reducing the effect of DC-biased magnetization and downsizing the magnetic core.

4) This trade-off is directly related to the coupling coefficient of the LCI. Therefore, the derivation for the optimal coupling coefficient is conducted to improve immunity to the unbalanced inductor average currents, and to downsize of the magnetic components.

This paper is divided into six sections. Section II discusses the causes of the DC-biased magnetization of the LCI. The electromagnetic analysis is conducted in section III, which is split into four subdivisions. The equations describing the peak flux in each leg is derived in subsection III A. The inductor ripple current equations are given in subsection III B. The relation between the peak flux and the inductor ripple current is 


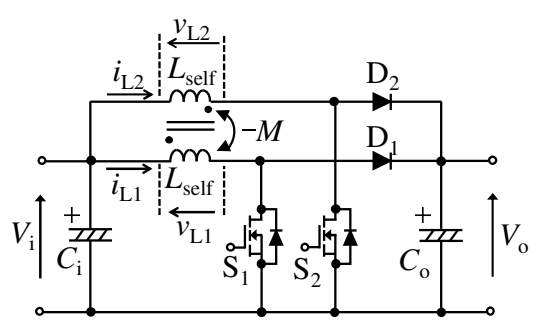

Fig. 1. Interleaved boost converter with a loosely coupled inductor.

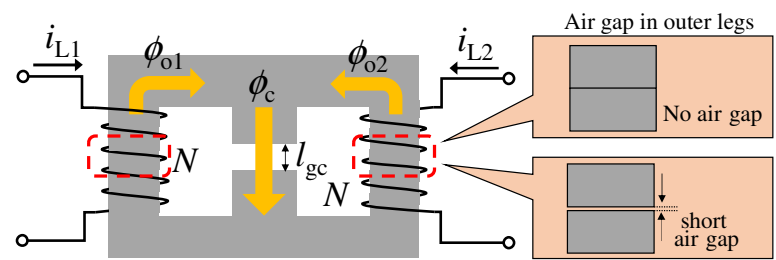

Fig. 2. Magnetic core structure of a loosely coupled inductor.

described in subsection III C. In subsection III D, a comparison of the core volumes is conducted between the coupled and the non-coupled inductor, taking into consideration the maximum permissible percentage of unbalanced inductor average currents and based on the peak flux equations derived in the previous subsections. Section IV presents the proposed design method, based on determining an optimal coupling coefficient to achieve peak flux reduction. The proposed design method is supported by simulation and experimental results in subsections V A and V B, respectively. A comparison of the features of the proposed design method with other design methods is presented in subsection V C. Finally, the conclusion is presented in section VI.

\section{THE CAUSES OF THE DC-BIASED MAGNETIZATION OF COUPLED INDUCTORS}

The circuit configuration of the interleaved boost converter with the LCI is shown in Fig. 1, where $V_{\mathrm{i}}$ and $V_{\mathrm{o}}$ are the input and output voltages, respectively; $i_{\mathrm{L} 1}$ and $i_{\mathrm{L} 2}$ are the inductor currents in each phase; $\mathrm{S}_{1}$ and $\mathrm{S}_{2}$ are the main switches; $C_{\mathrm{i}}$ and $C_{\mathrm{o}}$ are the input and output smoothing capacitance; $\mathrm{D}_{1}$ and $\mathrm{D}_{2}$ are the output diodes in each phase; $L_{\text {self }}$ and $M$ are the selfinductance and the mutual inductance of LCI with the same winding turns $N$. Fig. 2 shows the magnetic core structure of the LCI with EE or EI shape. The winding in each phase is inversely coupled with the other one in order to cancel the DC fluxes generated by the inductor average currents. Unbalanced conditions that adversely affects the circuit performance in Fig. 1 and their influence are considered as follows:

1) The duty ratio difference between $S_{1}$ and $S_{2}$ or the difference of parasitic resistance in each phase: these difference affect directly the difference between inductor average currents in each phase. However, by employing inductor average current controls, the average currents in each phase can be balanced by slightly modulating the duty ratio. The difference of duty ratio generated by average current controls is extremely small, hence the influence on the inductor current ripple and the peak-to-peak amplitude of AC flux are fairly small, respectively.

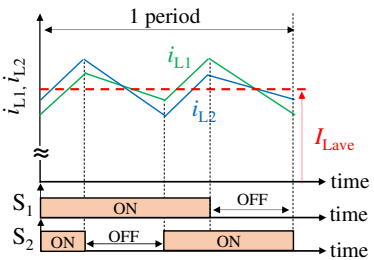

(a) Balanced condition Fig. 3. Inductor current waveforms under the balanced and unbalanced conditions.

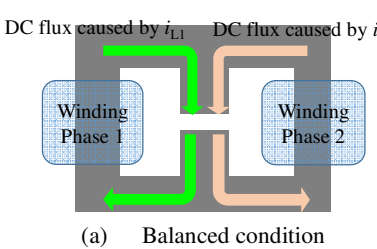

(a) Balanced condition

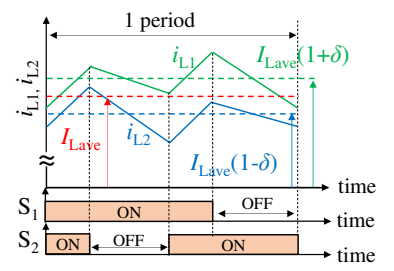

(b) Unbalanced condition

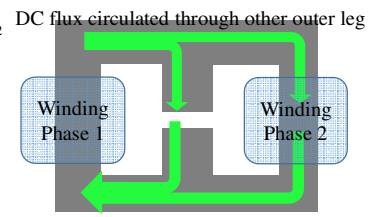

(b) Unbalanced condition conditions.

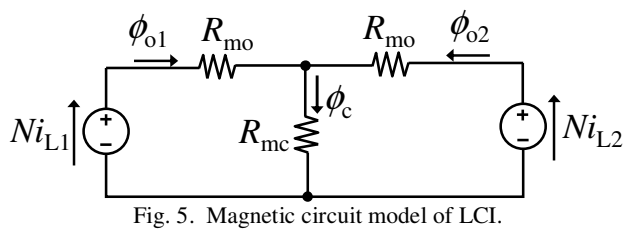

2) The difference between LCI's self-inductance in each phase: in this case, the difference between self-inductances in each phase is related to the difference between the leakage inductances in each phase if the number of turns in each phase are the same. Although the difference between the leakage inductances in each phase is naturally affected inductor ripple currents in each phase, this difference has to be paid attention from the flux density design points of view. This is because the leakage inductance of LCI is wellknown as the inductance related to DC flux [3], [5]. If flux density is regulated, LCI can be designed by setting an upper limit value of the leakage inductance.

3) Unbalanced average current condition: Unbalanced inductor average currents mainly affect DC-biased magnetization of the transformer part of LCI and this condition generates the undesirable flux. Even if inductor average current control is implemented, the current imbalance cannot be completely avoided as mentioned in section I. Therefore, in this section, the causes of the DCbiased magnetization of LCI are described in detail.

Figs. 3 (a) and (b) show the inductor current waveforms under balanced and unbalanced inductor current conditions, respectively. The inductor ripple current of LCI has a frequency equal to almost twice the switching frequency due to the effect of mutual induction. The inductor ripple current is composed of two current components: One is a common ripple current which is equal to half of the input ripple current, and the other is a wheeling ripple current of the transformer [5], [8]. LCI has both the leakage inductances and the mutual inductance, and the inductances related to each current component are different. The current ripple analysis results are shown in Appendix I. In Fig. 3, $I_{\text {Lave }}$ is the inductor average current in each phase, and $\delta$ $(0 \leq \delta<1)$ is the maximum permissible percentage of unbalanced inductor average current. $\delta=0$ means that the inductor average 
currents are completely balanced between the phases. In the same way, a higher $\delta$ means a large difference between the inductor average currents. If the input power $P_{\mathrm{i}}$ and input voltage $V_{\mathrm{i}}$ are not changed under both balanced and unbalanced conditions, the inductor average currents under the unbalanced condition can be represented as $I_{\text {Lave }}(1+\delta), I_{\text {Lave }}(1-\delta)$ for phase one and phase two, respectively. This relationship can be shown as follows

$$
\begin{aligned}
P_{\mathrm{i}} & =V_{\mathrm{i}} \cdot\left\{I_{\text {Lave }}(1+\delta)+I_{\text {Lave }}(1-\delta)\right\} \\
& =V_{\mathrm{i}} \cdot 2 I_{\text {Lave }}
\end{aligned}
$$

From this relationship, the unbalanced inductor average currents are symmetrically arranged around $I_{\text {Lave }}$. In the same way, Figs. 4 (a) and (b) show the DC flux behavior under balanced and unbalanced inductor average current conditions. For the balanced condition, as shown in Fig. 4 (a), the DC fluxes in the outer legs are usually equal, and they circulate through the central leg, since the DC magneto-motive force (MMF) in each phase is the same.

However, when there are unbalanced average currents flowing in the windings as shown in Fig. 4 (b), the DC flux in the outer leg, where a higher average inductor current flows, becomes significantly high in comparison with the balanced condition. The main reasons are that the magnetic reluctance of the transformer part in the outer leg is low to improve the effect of mutual inductance, and the DC-MMF between each phase is different. Consequently, DC-biased magnetization occurs when there is a difference between the inductor average currents.

\section{CHARACTERISTIC ANALYSIS UNDER THE DC-BIASED MAGNETIZATION}

In this section, electromagnetic analysis is carried out considering the DC-biased magnetization phenomenon. This analysis provides guidelines for the proposed design method presented in section IV. Essentially, a magnetic component is designed considering the maximum flux density by choosing the appropriate magnetic material and the core size in order to avoid magnetic saturation. The relationship between the maximum flux density $B_{\max }$, the maximum flux $\Phi_{\max }$, and the sectional area $A_{\text {core }}$ of the core is given as follows

$$
\Phi_{\text {max }}=B_{\text {max }} \cdot A_{\text {core }}
$$

Therefore, $\Phi_{\max }$ is one of the key factors that influence the magnetic core size and volume because $A_{\text {core }}$ size is influenced by $\Phi_{\max }$, and the magnetic design has to incorporate $B_{\max }$. Therefore, the peak flux analysis of the core relies on the magnetic circuit model of the LCI shown in Fig. 5, where $R_{\text {mo }}$ and $R_{\mathrm{mc}}$ are the magnetic reluctances in the outer legs and the central leg of EE shape cores. $\phi_{\mathrm{o} 1}, \phi_{\mathrm{o} 2}, \phi_{\mathrm{c}}$ are the magnetic fluxes in the outer legs and the central leg, respectively. In this magnetic circuit model, the external leakage fluxes of the windings are neglected to simplify the analysis.

\section{A. Magnetic analysis of peak fluxes in each leg}

In this subsection, the peak flux in the outer and central legs will be derived. First, DC fluxes are analyzed under the unbalanced inductor average current condition. The average inductor currents in each phase and DC fluxes in the outer leg and the central leg are denoted as $I_{\text {Lave }}(1+\delta), I_{\text {Lave }}(1-\delta), \Phi_{\mathrm{o} 1}, \Phi_{\mathrm{o} 2}$, and $\Phi_{\mathrm{c}}$, respectively. Based on the magnetic circuit model shown in Fig. 5, the following equations can be obtained

$$
\left\{\begin{array}{l}
N \cdot I_{\text {Lave } 1}=N \cdot I_{\text {Lave }}(1+\delta)=R_{\mathrm{mo}} \cdot \Phi_{\mathrm{o} 1}+R_{\mathrm{mc}} \cdot \Phi_{\mathrm{c}} \\
N \cdot I_{\text {Lave } 2}=N \cdot I_{\text {Lave }}(1-\delta)=R_{\mathrm{mo}} \cdot \Phi_{\mathrm{o} 2}+R_{\mathrm{mc}} \cdot \Phi_{\mathrm{c}} \\
\Phi_{\mathrm{c}}=\Phi_{\mathrm{o} 1}+\Phi_{\mathrm{o} 2}
\end{array}\right.
$$

Thus, $\Phi_{\mathrm{o} 1}, \Phi_{\mathrm{o} 2}, \Phi_{\mathrm{c}}$ are respectively shown by

$$
\left\{\begin{array}{l}
\Phi_{\mathrm{o} 1}=N \cdot I_{\text {Lave }}\left(\frac{1}{R_{\mathrm{mo}}+2 R_{\mathrm{mc}}}+\frac{\delta}{R_{\mathrm{mo}}}\right) \\
\Phi_{\mathrm{o} 2}=N \cdot I_{\text {Lave }}\left(\frac{1}{R_{\mathrm{mo}}+2 R_{\mathrm{mc}}}-\frac{\delta}{R_{\mathrm{mo}}}\right) \\
\Phi_{\mathrm{c}}=\frac{2 \cdot N \cdot I_{\text {Lave }}}{R_{\mathrm{mo}}+2 R_{\mathrm{mc}}}
\end{array}\right.
$$

Then, the peak-to-peak amplitude of the AC flux in the outer leg is given by the following equation on the basis of Faraday's law

$$
\Phi_{\text {opp }}=\frac{V_{\mathrm{i}}}{N} \cdot d \cdot T_{\mathrm{s}}
$$

where $d$ and $T_{\mathrm{s}}$ are the duty ratios of the main switch and the switching period. On the other hand, the AC fluxes in the central leg are expressed as follows

$$
\left\{\begin{array}{l}
\Phi_{\text {cpp_d } \leq 0.5}=\frac{1-2 d}{1-d} \cdot \frac{V_{\mathrm{i}}}{N} \cdot d \cdot T_{\mathrm{s}} \\
\Phi_{\text {cpp_d }>0.5}=\frac{2 d-1}{d} \cdot \frac{V_{\mathrm{i}}}{N} \cdot d \cdot T_{\mathrm{s}}
\end{array}\right.
$$

From (6), AC fluxes in the central leg depend on whether the duty ratio is less than or greater than 0.5 . This is so because AC fluxes having $180^{\circ}$ phase difference in the two outer legs are added at the central leg.

On the other hand, the higher peak flux in the outer leg, where the higher inductor average current flows, is shown by the following equation, considering that the peak flux is shown by the sum of the DC flux and half of the AC flux.

$\Phi_{\mathrm{op}}=\Phi_{\mathrm{o}}+\frac{1}{2} \Phi_{\mathrm{opp}}=N \cdot I_{\text {Lave }} \cdot\left(\frac{1}{R_{\mathrm{mo}} \cdot(1+2 \alpha)}+\frac{\delta}{R_{\mathrm{mo}}}\right)+\frac{1}{2} \cdot \frac{V_{\mathrm{i}}}{N} \cdot d \cdot T_{\mathrm{s}}$

where $\alpha$ is the ratio of $R_{\mathrm{mc}}$ to $R_{\mathrm{mo}}\left(\alpha=R_{\mathrm{mc}} / R_{\mathrm{mo}}\right)$. Similarly, the peak flux in the central leg when the duty ratio is less or greater than 0.5 is respectively given by

$$
\left\{\begin{array}{l}
\Phi_{\text {cp_d } \leq 0.5}=\Phi_{\mathrm{c}}+\frac{1}{2} \Phi_{\text {cpp_d } \leq 0.5}=\frac{2 \cdot N \cdot I_{\text {Lave }}}{R_{\text {mo }} \cdot(1+2 \alpha)}+\frac{1}{2} \cdot \frac{1-2 d}{1-d} \cdot \frac{V_{\mathrm{i}}}{N} \cdot d \cdot T_{\mathrm{s}} \\
\Phi_{\text {cp_d }>0.5}=\Phi_{\mathrm{c}}+\frac{1}{2} \Phi_{\text {cpp_d }>0.5}=\frac{2 \cdot N \cdot I_{\text {Lave }}}{R_{\text {mo }} \cdot(1+2 \alpha)}+\frac{1}{2} \cdot \frac{2 d-1}{d} \cdot \frac{V_{\mathrm{i}}}{N} \cdot d \cdot T_{\mathrm{s}}
\end{array}\right.
$$

Based on the magnetic circuit model shown in Fig. 5, the mutual inductance $M$ and the leakage inductance $L_{\mathrm{lk}}$ are described as follows

$$
\left\{\begin{array}{l}
M=N^{2} \cdot \frac{R_{\mathrm{mc}}}{R_{\mathrm{mo}}^{2}+2 \cdot R_{\mathrm{mo}} \cdot R_{\mathrm{mc}}} \\
L_{\mathrm{lk}}=N^{2} \cdot \frac{1}{R_{\mathrm{mo}}+2 \cdot R_{\mathrm{mc}}}
\end{array}\right.
$$

Therefore, the relationship between the coupling coefficient $k$ and the ratio of magnetic reluctance $\alpha$ is as follows

$$
k=\frac{M}{L_{\text {self }}}=\frac{M}{M+L_{\mathrm{k}}}=\frac{\alpha}{1+\alpha}, \quad \alpha=\frac{k}{1-k}
$$


From (10), it can be deduced that the coupling coefficient $k$ is related to the ratio of magnetic reluctance only. In addition, by solving (4), (9), and (10) together, the DC flux related to the unbalanced current, $\Phi_{\mathrm{o} \delta} \delta$ can be expressed as follows

$$
\begin{aligned}
\Phi_{\mathrm{o}_{-} \delta} & =N \cdot I_{\text {Lave }} \cdot \frac{\delta}{R_{\mathrm{mo}}}=N \cdot I_{\text {Lave }} \cdot \delta \cdot\left(L_{\mathrm{lk}}+2 M\right) \\
& =N \cdot I_{\text {Lave }} \cdot \delta \cdot L_{\text {self }} \cdot(1+k)
\end{aligned}
$$

Based on (11), it can be concluded that in the case of high coupling factor $k$, the influence of a small current unbalance (i.e., small value of $\delta$ ) on the DC flux will be significantly high in the LCI configuration [26]-[27]. Therefore, it is important to insert a small air gap into the outer legs to improve the immunity to the unbalanced currents, and to minimize the effect of DC-biased magnetization by adjusting the value of the coupling factor $k$.

\section{B. Inductor ripple current analysis}

Inductor ripple current is an important factor in designing magnetic devices. Because the ripple current flows in the inductor windings, it influences the maximum current ratings of the power devices, the power conversion efficiency, and the load range that can be operated in the Continuous Current Mode (CCM). In this paper, CCM is assumed because the interleaved multi-phase boost converter is often applied in high power applications, and inductors are usually designed at the maximum power rating in the converter.

In CCM operation ranges, the inductor ripple current is expressed by the following equation, regardless of whether the current is balanced or unbalanced.

$$
\left\{\begin{array}{l}
I_{\text {Lpp_d } \_0.5}=R_{\text {mo }}\left(1+\alpha \cdot \frac{1-2 \cdot d}{1-d}\right) \cdot \frac{V_{\mathrm{i}}}{N^{2}} \cdot d \cdot T_{\mathrm{s}} \\
I_{\text {Lpp_d }>0.5}=R_{\text {mo }}\left(1+\alpha \cdot \frac{2 \cdot d-1}{d}\right) \cdot \frac{V_{\mathrm{i}}}{N^{2}} \cdot d \cdot T_{\mathrm{s}}
\end{array}\right.
$$

\section{Peak flux normalized by the inductor ripple current}

Based on (7)-(8), and (12), it is clear that the magnetic circuit parameters $R_{\mathrm{mo}}, R_{\mathrm{mc}}$, and $N$, influence both the peak flux and the inductor ripple current. Therefore, to evaluate the downsizing effect of the LCI under the DC-biased magnetization condition, the maximum fluxes in the outer and the center legs shall be derived as a function of the inductor ripple current.

The peak fluxes in the outer leg within the ranges of the duty ratio $d \leq 0.5, d>0.5$ are given by the following equations, which are obtained by substituting (12) into (7) to eliminate $R_{\text {mo }}$ $\left\{\begin{array}{l}\Phi_{\text {op_d } \_0.5}=\frac{V_{\mathrm{i}}}{N} \cdot\left(\frac{\delta \cdot(1+2 \cdot \alpha)+1}{1+2 \cdot \alpha} \cdot\left(1+\alpha \cdot \frac{1-2 \cdot d}{1-d}\right) \cdot \frac{I_{\mathrm{Lave}}}{I_{\mathrm{Lpp}}}+\frac{1}{2}\right) \cdot d \cdot T_{\mathrm{s}} \\ \Phi_{\mathrm{op} \_\mathrm{d}>0.5}=\frac{V_{\mathrm{i}}}{N} \cdot\left(\frac{\delta \cdot(1+2 \cdot \alpha)+1}{1+2 \cdot \alpha} \cdot\left(1+\alpha \cdot \frac{2 \cdot d-1}{d}\right) \cdot \frac{I_{\mathrm{Lave}}}{I_{\mathrm{Lpp}}}+\frac{1}{2}\right) \cdot d \cdot T_{\mathrm{s}}\end{array}\right.$

In the same way, the peak fluxes in the central leg are given by

$$
\begin{aligned}
& \left\{\Phi_{\text {cp_k } 0.5}=\frac{V_{\mathrm{i}}}{N} \cdot\left(\frac{2}{1+2 \cdot \alpha} \cdot\left(1+\alpha \cdot \frac{1-2 \cdot d}{1-d}\right) \cdot \frac{I_{\text {Lave }}}{I_{\mathrm{Lpp}}}+\frac{1}{2} \cdot \frac{1-2 \cdot d}{1-d}\right) \cdot d \cdot T_{\mathrm{s}}\right. \\
& \Phi_{\text {cp_ } ₫ 0.5}=\frac{V_{\mathrm{i}}}{N} \cdot\left(\frac{2}{1+2 \cdot \alpha} \cdot\left(1+\alpha \cdot \frac{2 \cdot d-1}{d}\right) \cdot \frac{I_{\mathrm{Lave}}}{I_{\mathrm{Lpp}}}+\frac{1}{2} \cdot \frac{2 \cdot d-1}{d}\right) \cdot d \cdot T_{\mathrm{s}}
\end{aligned}
$$

On the other hand, in the case of the non-coupled inductor, the peak flux can be expressed as a function of the current unbalance as follows

$$
\Phi_{\mathrm{np}}=\frac{V_{\mathrm{i}}}{N} \cdot\left\{\frac{I_{\mathrm{Lave}}}{I_{\mathrm{Lpp}}} \cdot(\delta+1)+\frac{1}{2}\right\} \cdot d \cdot T_{\mathrm{s}}
$$

Equation (15) is derived to help investigate the reduction of the magnetic core volume of the LCI compared with that of the non-coupled inductor.

\section{Comparisons of peak fluxes and core volume}

Equations (13)-(15) describe the peak fluxes in the outer leg, the central leg of the LCI and the non-coupled inductor, respectively. These equations will help us to evaluate the core volume in each case for DC-biased magnetization. In addition, this evaluation is helpful in selecting a suitable magnetic core, since it provides information about which leg has the higher flux density in the LCI configuration. The evaluation items to compare each peak flux, $\Phi_{\mathrm{cp}}(\delta=0-0.02) / \Phi_{\mathrm{op}}(\delta=0-0.02), \Phi_{\mathrm{op}}$ $(\delta=0.01-0.03) / \Phi_{\text {op }}(\delta=0)$, and $\Phi_{\text {op }}(\delta=0-0.02) / \Phi_{\text {np }}(\delta=0-$ $0.02)$ are respectively compared to confirm the influence of DC-biased magnetization. These comparison results are also useful in describing the relationship between the section area of the central and the outer legs to obtain a uniform and constant value of flux density in the magnetic core. All comparisons are carried out under the condition that the ratio of the ripple current to the average current $I_{\mathrm{Lpp}} / I_{\mathrm{Lave}}$ is 0.3 .

First, using (13) and (14), the ratio of $\Phi_{\mathrm{cp}}(\delta=0-0.02)$ to $\Phi_{\mathrm{op}}$ $(\delta=0-0.02)$ is obtained, as shown in Figs. 6 (a)-(c). As a comparison condition, $\delta$ is varied from 0 to 0.02 . As seen in Figs. 6 (a)-(c), the peak flux $\Phi_{\text {cp }}$ in the central leg is always less than twice its value in the outer leg in all ranges of the duty ratio and under any $\delta$ conditions. Usually, magnetic cores with the EE or EI shape have twice the sectional area in the central leg as compared with the outer legs. In this context, if the sectional area in the central leg is larger than twice its value in the outer leg, the flux density in the outer leg is always the highest in the core. In addition, when unbalanced current flows into the winding of the LCI with a high coupling coefficient, the peak flux $\Phi_{\text {op }}$ in the outer leg increases significantly in comparison with $\Phi_{\mathrm{cp}}$ in the central leg, because a higher coupling coefficient $k$ means lower magnetic reluctance $R_{\text {mo }}$, which helps to generate a larger DC flux in the outer leg under unbalanced current conditions.

Second, Figs. 7 (a)-(c) show the ratio of the peak flux $\Phi_{\mathrm{op}}$ with DC-biased magnetization $(\delta=0.01-0.03)$ to $\Phi_{\text {op }}$ without DC-biased magnetization $(\delta=0)$. This comparison is conducted to investigate the influence of the unbalanced current factor $\delta$ under the same coupling coefficient condition. As shown in Figs. 7 (a)-(c), if the LCI is designed with a higher $k$ (i.e., $k=$ 0.99 ) and unbalanced current occurs between each phase, it leads to an increase of the peak flux $\Phi_{\text {op }}$ in the outer leg under unbalanced conditions and, consequently, magnetic saturation may occur if the LCI is designed assuming balanced current conditions. When magnetic saturation occurs, the inductance values of the LCI drop dramatically and the inductor current ripple increases considerably, causing conduction losses (in both of the inductor winding and power devices) to increase. In the worst case, the converter may be stopped by the overcurrent 


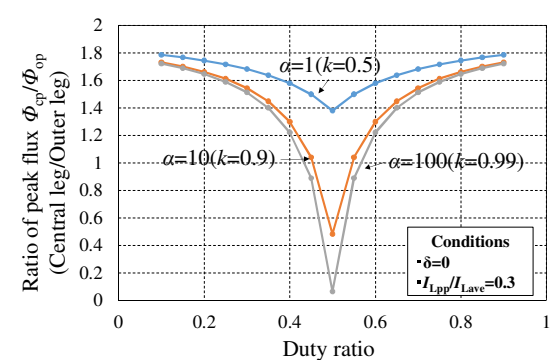

(a) $\delta=0$

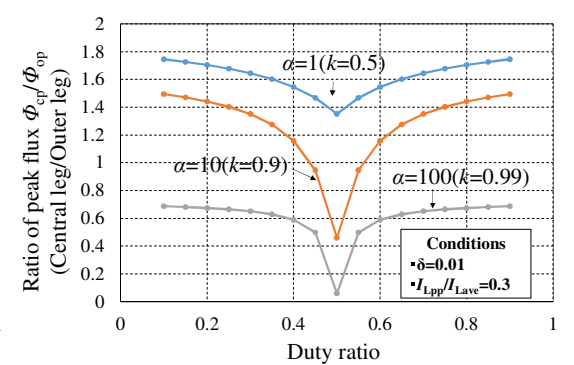

(b) $\delta=0.01$

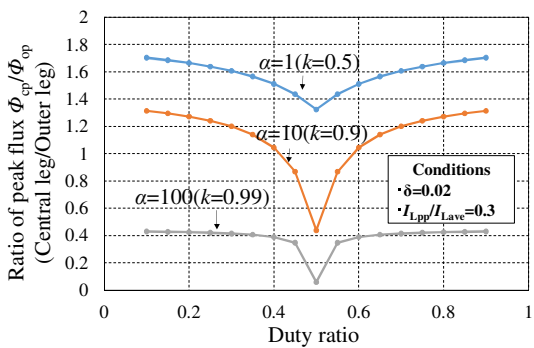

(c) $\delta=0.02$

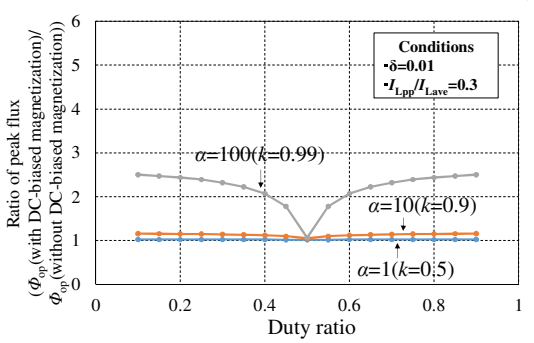

(a) $\delta=0.01$

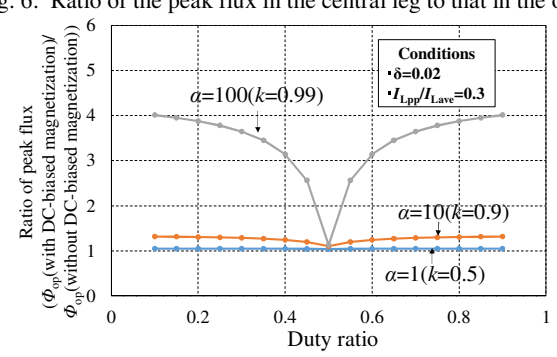

(b) $\delta=0.02$

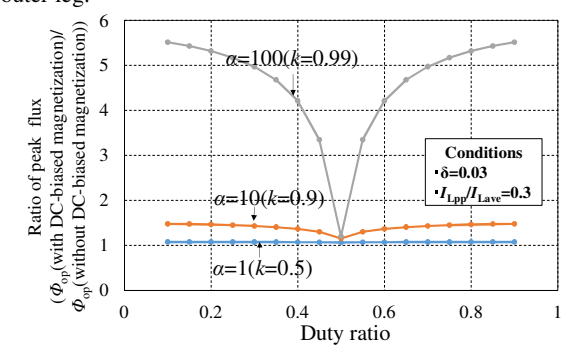

(c) $\delta=0.03$

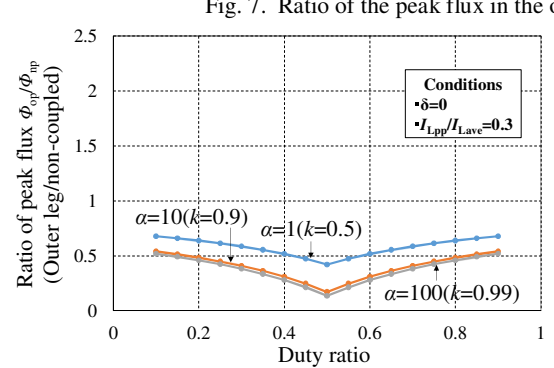

(a) $\delta=0$

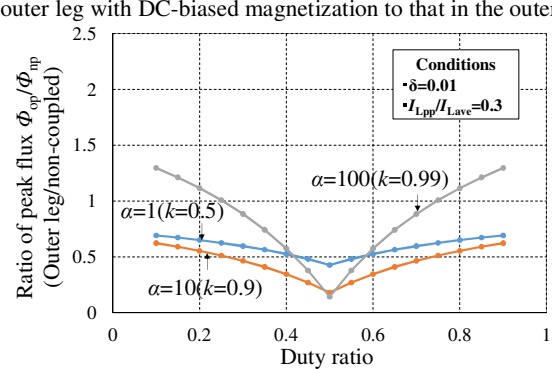

(b) $\delta=0.01$

Fig. 8. Ratio of the peak flux in the outer leg to that in the non-coupled inductor

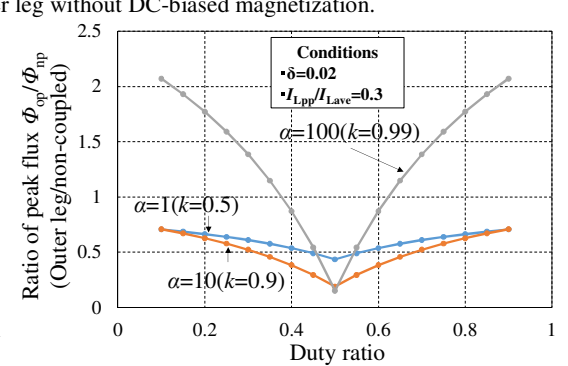

(c) $\delta=0.02$ protection mechanism. As previously mentioned, the vertical axis shown in Figs. 7 (a)-(c) means that the ratio of peak flux with DC-biased magnetization to that without DC-biased magnetization. In other words, the vertical axis also means the ratio of the sectional area in the outer leg designed to handle the same flux density under the balanced and unbalanced conditions respectively, as understood from (2). Therefore, the outbreak of the unbalanced current is related to a reduction in the downsizing effect of LCI. On the other hand, within lower values of the coupling coefficient (i.e., $k=0.5$ ), the ratio of the peak flux under unbalanced $\Phi_{\mathrm{op}}(\delta=0.01-0.03)$ to that under balanced $\Phi_{\mathrm{op}}(\delta=0)$ is considerably small. This is also consistent with (11). However, a lower coupling coefficient considerably reduces the downsizing effect of LCI as compared with non-coupled inductors as follows.

Finally, using (13) and (15), peak flux $\Phi_{\text {op }}(\delta=0-0.02)$ in the outer leg is compared with $\Phi_{\mathrm{np}}(\delta=0-0.02)$ in the non-coupled inductor. In this comparison, both the coupled and the noncoupled inductors have the same number of turns because the number of turns also affects the values of their peak fluxes. The purpose of this investigation is to confirm the reduction in the downsizing effect of LCI in comparison with a non-coupled inductor when $k$ and $\delta$ are varied. Figs. 8 (a)-(c) show the ratio of $\Phi_{\mathrm{op}}$ to $\Phi_{\mathrm{np}}$ under the same $\delta$ conditions. The vertical axis in this figure also means that the ratio of sectional area $A_{\mathrm{o}}$ in the outer leg to $A_{\text {non }}$ of the non-coupled inductor is designed to have the same flux density. As seen in Figs. 8 (a)-(c), if LCI with a higher $k$ is used under the $\delta=0$ condition, greater reduction in $\Phi_{\text {op }}$ can be obtained as compared with that of a non-coupled inductor. Therefore, the downsizing of the sectional area $A_{\mathrm{o}}$ in the outer leg of LCI can be realized as compared with that of a non-coupled inductor. This means that a higher coupling coefficient helps to reduce the overall core volume of LCI under the current balancing condition $\delta=0$. On the other hand, when higher unbalanced currents flow into the windings of LCI with higher $k, \Phi_{\text {op }}$ greatly increases compared with $\Phi_{\text {np }}$. Therefore, a higher $k$ is not always suitable for downsizing of magnetic core under unbalanced average current condition. As shown in Figs. (6)-(8), the coupling coefficient value of 0.99 is given as an extreme example to investigate the influence on DC-biased magnetization. However, a high coupling coefficient such as 0.99 or a value close to it, could be obtained by using high permeability magnetic materials such as nanocrystalline, amorphous cores or electrical steel sheets.

Then, to clarify the effect of DC-biased magnetization on the core volume of LCI, a calculation method of core volume based on the area product method [27], [35] is introduced. The calculation of core volume is carried out by estimation. The definitions of the core size for the estimated core are shown in Fig. 9. The shape of the sectional area $A_{o}$ in the outer leg of LCI, 


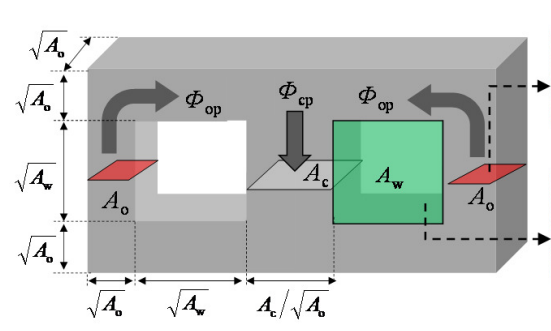

(a) Coupled inductor

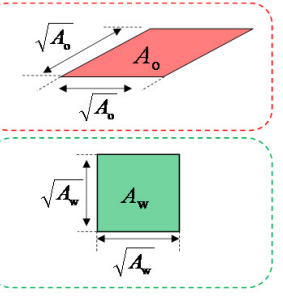

Fig. 9. Definitions of the estimated core.

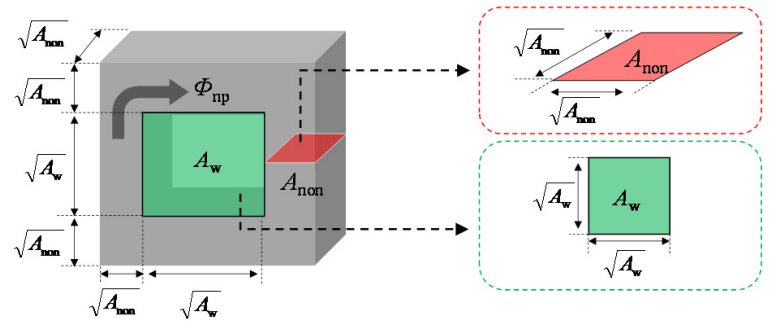

(b) Non-coupled inductor for per a phase

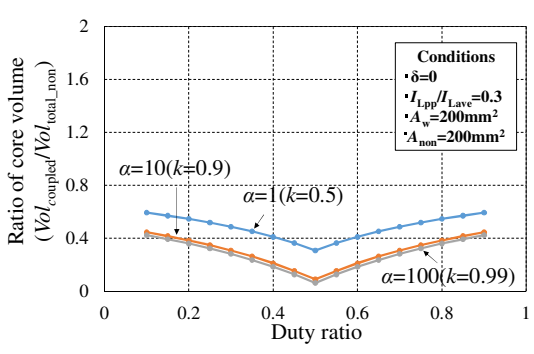

(a) $\delta=0$

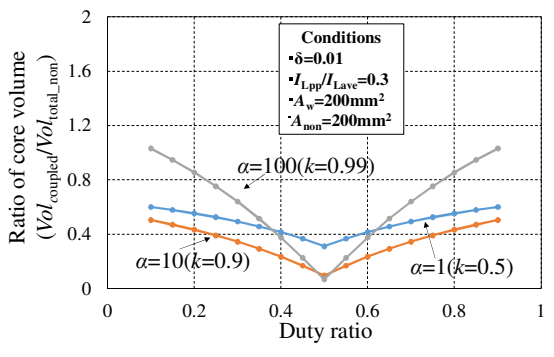

(b) $\delta=0.01$

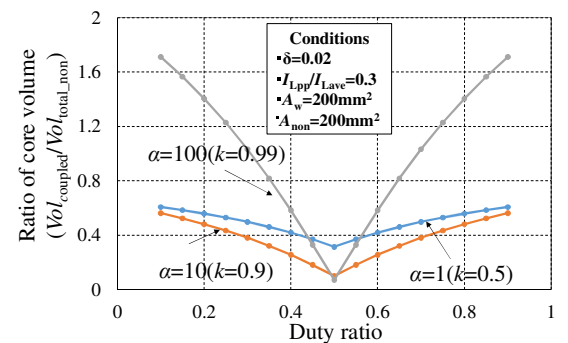

(c) $\delta=0.02$

Fig. 10. Ratio of the core volume of LCI to that of non-coupled inductors.

$A_{\text {non }}$ of the non-coupled inductor, and the winding area $A_{\mathrm{w}}$ to wind the windings to the core, are defined as square for analytical convenience. In this structure, the core volume of LCI, $V o l_{\text {coupled }}$ can be calculated as follows

$$
\begin{aligned}
V o l_{\text {coupled }} & =\underbrace{\left\{\left(\sqrt{A_{\mathrm{o}}}+\sqrt{A_{\mathrm{w}}}\right) \cdot\left(2 \sqrt{A_{\mathrm{o}}}+\sqrt{A_{\mathrm{w}}}\right) \cdot \sqrt{A_{\mathrm{o}}}-A_{\mathrm{w}} \cdot \sqrt{A_{\mathrm{o}}}\right\}}_{\text {Core volume in outer leg }} \cdot 2 \\
& +\underbrace{\left(2 \sqrt{A_{\mathrm{o}}}+\sqrt{A_{\mathrm{w}}}\right) \cdot \frac{A_{\mathrm{c}}}{\sqrt{A_{\mathrm{o}}}} \cdot \sqrt{A_{\mathrm{o}}}}_{\text {Core volume in centralleg }} \\
& =2 \cdot \sqrt{A_{\mathrm{o}}} \cdot\left(A_{\mathrm{c}}+2 A_{\mathrm{o}}\right)+\left(A_{\mathrm{c}}+6 A_{\mathrm{o}}\right) \cdot \sqrt{A_{\mathrm{w}}}
\end{aligned}
$$

Then, $A_{\mathrm{o}}$ and $A_{\mathrm{c}}$ described in (16) can be converted as follows

$$
\left\{\begin{array}{l}
A_{\mathrm{o}}=\frac{\Phi_{\mathrm{op}}}{B_{\mathrm{max}}}=\frac{\Phi_{\mathrm{np}}}{B_{\mathrm{max}}} \cdot \frac{\Phi_{\mathrm{op}}}{\Phi_{\mathrm{np}}}=A_{\mathrm{non}} \cdot \frac{\Phi_{\mathrm{op}}}{\Phi_{\mathrm{np}}} \\
A_{\mathrm{c}}=\frac{\Phi_{\mathrm{cp}}}{B_{\mathrm{max}}}=\frac{\Phi_{\mathrm{np}}}{B_{\max }} \cdot \frac{\Phi_{\mathrm{op}}}{\Phi_{\mathrm{np}}} \cdot \frac{\Phi_{\mathrm{cp}}}{\Phi_{\mathrm{op}}}=A_{\mathrm{non}} \cdot \frac{\Phi_{\mathrm{op}}}{\Phi_{\mathrm{np}}} \cdot \frac{\Phi_{\mathrm{cp}}}{\Phi_{\mathrm{op}}}
\end{array}\right.
$$

Likewise, the total core volume of the non-coupled inductors, Vol $l_{\text {total_non }}$ can be calculated as follows

$$
\begin{aligned}
V o l_{\text {total_non }} & =\underbrace{\left\{\left(2 \sqrt{A_{\text {non }}}+\sqrt{A_{\mathrm{w}}}\right)^{2} \cdot \sqrt{A_{\text {non }}}-A_{\mathrm{w}} \cdot \sqrt{A_{\text {non }}}\right.}_{\text {core volume per a phase }}\} \cdot 2 \\
& =8 \cdot A_{\text {non }} \cdot\left(\sqrt{A_{\text {non }}}+\sqrt{A_{\text {w }}}\right)
\end{aligned}
$$

Therefore, the ratio of $V o l_{\text {coupled }}$ to $V o l_{\text {total_non }}$ is given by the following

$$
\frac{V o l_{\text {coupled }}}{V o l_{\text {total_non }}}=\frac{\frac{\Phi_{\mathrm{op}}}{\Phi_{\mathrm{np}}}\left(\sqrt{A_{\mathrm{w}}} \cdot\left(6+\frac{\Phi_{\mathrm{cp}}}{\Phi_{\mathrm{op}}}\right)+2\left(2+\frac{\Phi_{\mathrm{cp}}}{\Phi_{\mathrm{op}}}\right) \cdot \sqrt{A_{\mathrm{non}} \cdot \frac{\Phi_{\mathrm{op}}}{\Phi_{\mathrm{np}}}}\right)}{8 \cdot\left(\sqrt{A_{\mathrm{non}}}+\sqrt{A_{\mathrm{w}}}\right)}
$$

Therefore, the estimated core volume of LCI and that of noncoupled inductors can be compared by utilizing (13)-(15) and (19). The ratio of $V o l_{\text {coupled }}$ to $V o l_{\text {total }}$ non is shown in Fig. 10. The preconditions to illustrate Fig. 10 are also shown in the same figure. As seen in this figure, $V o l_{\text {coupled }}$ can be significantly reduced at higher coupling coefficients when $\delta=0$. However, with increasing $\delta$, higher $k$ degrades the downsizing effect of
LCI. We summarize as follows:

- Under balanced current condition: LCI with a high coupling coefficient is effective to downsize the core volume. As the peak flux in the outer leg can be reduced, the sectional area of the outer leg can be downsized.

- Under unbalanced current conditions: LCI with a high coupling coefficient leads to an increase in the volume of the magnetic core to avoid magnetic saturation.

It can be concluded that there is a trade-off between handling the DC-biased magnetization and downsizing the magnetic components. This trade-off is directly related to the coupling coefficient of the LCI. Therefore, selecting the optimum value of the coupling factor is important to obtain immunity to the phase unbalanced currents and downsizing the magnetic core volume.

\section{MAGNETIC DESIGN METHOD FOR COUPLED INDUCTOR}

\section{A. Determining optimal coupling coefficient}

The purpose of the proposed design method is to obtain optimal magnetic circuit parameters such as $R_{\mathrm{mo}}, R_{\mathrm{mc}}$, and $N$ under any unbalanced condition. In order to downsize the magnetic core of the LCI compared with non-coupled inductors, the optimal coupling coefficient $k$ considering any unbalanced current factor $\delta$ shall be derived. Furthermore, the core volume of the outer legs of the LCI occupy a large proportion of the total volume of LCI as seen in Fig. 9, because the central leg is a part of the core. Therefore, the condition that the ratio of peak flux $\Phi_{\text {op }}$ to $\Phi_{\text {np }}$ become the lowest value is one of the optimal design points to downsize the core volume of LCI. To identify an optimal $\alpha$ (or an optimal $k$ ), Fig. 11 shows the ratio of $\Phi_{\text {op }}$ to $\Phi_{\text {np }}$ when $\delta=0.001-0.1$ and $d$ is fixed at 0.7. As shown in Fig. 11 , there is one optimal value of $\alpha$ where $\Phi_{\mathrm{op}} / \Phi_{\mathrm{np}}$ is minimum. To identify the optimal $\alpha$, the following equations have to be satisfied 


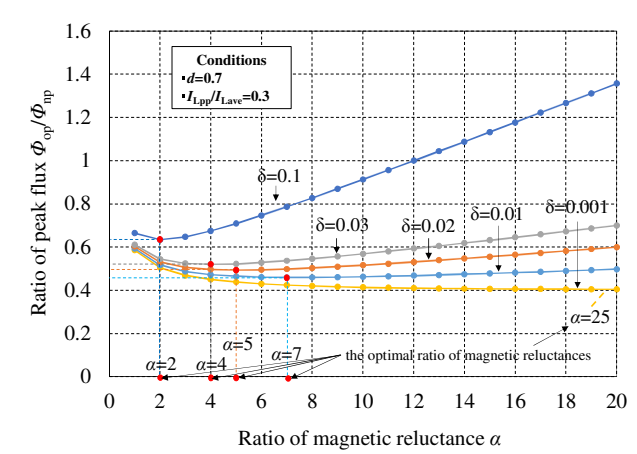

Fig. 11. The relationship between ratio of peak flux $\left(\Phi_{\mathrm{op}} / \Phi_{\mathrm{np}}\right)$ and ratio of magnetic reluctance $\alpha$.

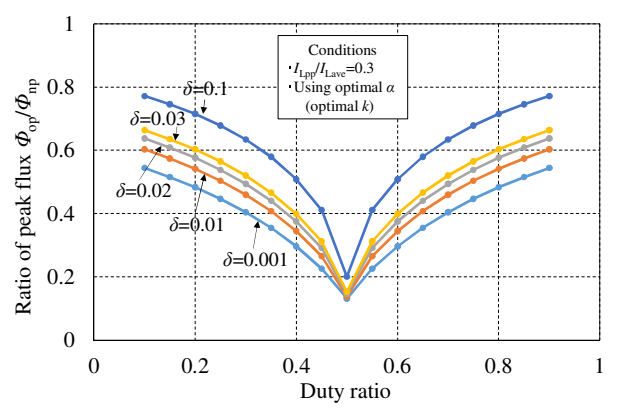

Fig. 13. Ratio of peak flux ( $\left.\Phi_{\mathrm{op}} / \Phi_{\mathrm{np}}\right)$ using the optimal $\alpha$ under DC-biased magnetization condition.

$$
\left\{\begin{array}{l}
\frac{d\left(\Phi_{\text {op_d } \_0.5} / \Phi_{\text {np }}\right)}{d \alpha}=0 \\
\frac{d\left(\Phi_{\text {op_d }>0.5} / \Phi_{\text {np }}\right)}{d \alpha}=0
\end{array}\right.
$$

By solving (20), the optimal $\alpha$ can be obtained within the ranges of duty ratio less or greater than 0.5 , respectively

$$
\left\{\begin{array}{l}
\alpha_{\mathrm{d} \leq 0.5}=\frac{\delta(1-2 d) \pm \sqrt{\delta(1-2 d)}}{2 \delta(2 d-1)} \\
\alpha_{\mathrm{d}>0.5}=\frac{\delta(2 d-1) \pm \sqrt{\delta(2 d-1)}}{2 \delta(1-2 d)}
\end{array}\right.
$$

Although there are two solutions in (21) within the ranges of $d \leq 0.5, d>0.5$, when the second term in (21) is positive, $\alpha$ is not effective because it always becomes negative. This value cannot be used in practical design. Therefore, the effective value of $\alpha$ can be obtained as follows

$$
\left\{\begin{array}{l}
\alpha_{\mathrm{d} \leq 0.5}=\frac{\delta(1-2 d)-\sqrt{\delta(1-2 d)}}{2 \delta(2 d-1)} \\
\alpha_{\mathrm{d}>0.5}=\frac{\delta(2 d-1)-\sqrt{\delta(2 d-1)}}{2 \delta(1-2 d)}
\end{array}\right.
$$

As shown in (22), the optimal $\alpha$ depends on only the duty ratio and the maximum permissible factor $\delta$. Using (10) and (22), the relationship between the optimal $k$ and duty ratio $d$ under any $\delta$ condition is shown in Fig. 12. As shown in Fig. 12, the coupling coefficient considering a maximum permissible factor $\delta$ is relatively high at $d=0.5$. However, a lower coupling coefficient is needed at extreme duty ratios such as $d=0.1$ and 0.9 or with increasing unbalanced current factor $\delta$, as a feature of the optimal $k$. Figs. 13 and 14 respectively show the ratio of $\Phi_{\mathrm{op}}(\delta=0.001-0.1) / \Phi_{\mathrm{np}}(\delta=0.001-0.1)$ and the ratio of $\Phi_{\mathrm{cp}}(\delta$ $=0.001-0.1) / \Phi_{\mathrm{op}}(\delta=0.001-0.1)$ when the optimal $\alpha$ derived

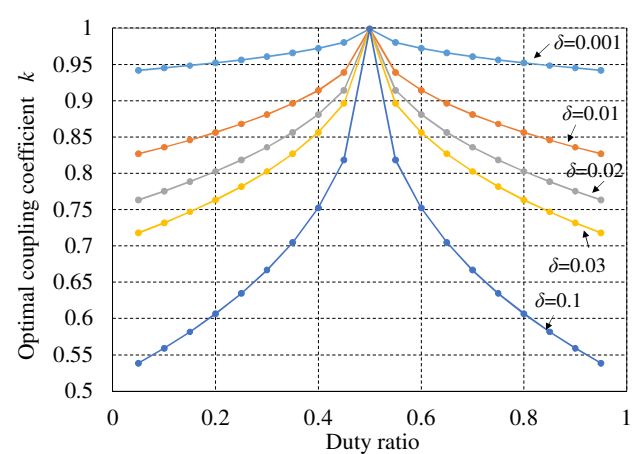

Fig. 12. Optimal coupling coefficient considering DC-Biased magnetization.

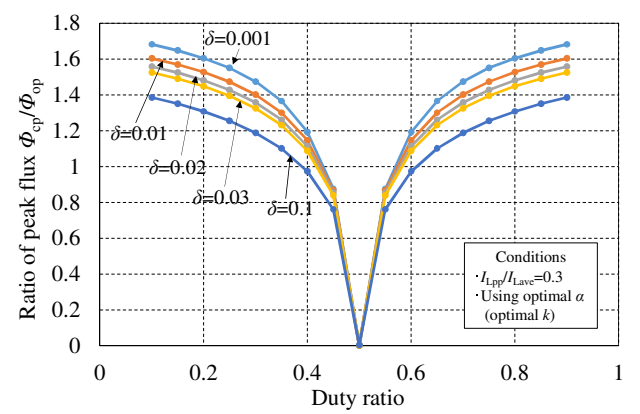

Fig. 14. Ratio of peak magnetic fluxes $\left(\Phi_{\mathrm{cp}} / \Phi_{\mathrm{op}}\right)$ using the optimal $\alpha$ under DC-biased magnetization condition.

from (22) is used. It can be seen that as the operating duty ratio $d$ approaches the duty ratio limits (for instance 0.1 or 0.9 ), the downsizing effect of the sectional area $A_{\mathrm{o}}$ in the outer leg becomes smaller compared with that of the non-coupled inductor. Therefore, when the two-phase interleaved boost converter with LCI is employed in renewable energy systems that require a high voltage gain [10], the downsizing effect is relatively low. On the other hand, as shown in Fig. 14, the ratio of peak flux ( $\left.\Phi_{\mathrm{cp}} / \Phi_{\mathrm{op}}\right)$ reduces with increasing $\delta$. This is because the unbalanced current factor $\delta$ only affect the increase of $\Phi_{\mathrm{op}}$, and $\Phi_{\mathrm{cp}} / \Phi_{\mathrm{op}}$ becomes smaller with increasing $\delta$.

Although the total core volume of LCI is mainly occupied by the outer legs, the core volume of the central leg also impacts the total volume of LCI. Therefore, to demonstrate the effectiveness of the optimal $k$, the core volume of LCI and that of the non-coupled inductor are compared when the coupling coefficient $k$ is $0.1-0.99$. In addition, since the optimal $k$ is affected by not only $d$ but also $\delta$, comparative studies on the two conditions are conducted to investigate the impact of not considering the peak flux in the central leg: One is assumed on the condition that $\delta$ is fixed as 0.03 , and $d$ is varied from 0.1 to 0.9 . The other is assumed on the condition that $d$ is fixed as 0.7 , and $\delta$ is varied from 0.001 to 0.1 . By substituting (10) into (13) and (14), and then calculating (19), the ratio of the core volume of LCI to that of non-coupled inductors can be obtained. The comparison results of the core volumes of LCI and the noncoupled inductor are shown in Figs. 15 (a) and (b), respectively. As seen in Figs. 15 (a) and (b), there is a slight error between the coupling coefficient that results in the maximum downsizing effect and the optimal $k$ plotted in red points in these figures. However, the optimal $k$ can be identified as the 


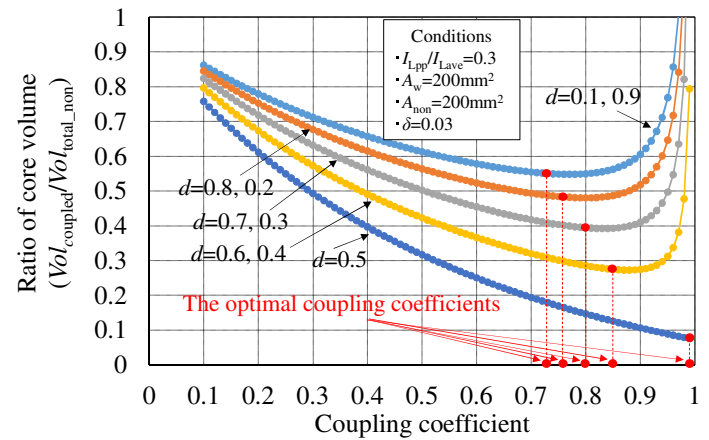

(a) The condition of $\delta$ is fixed as 0.03

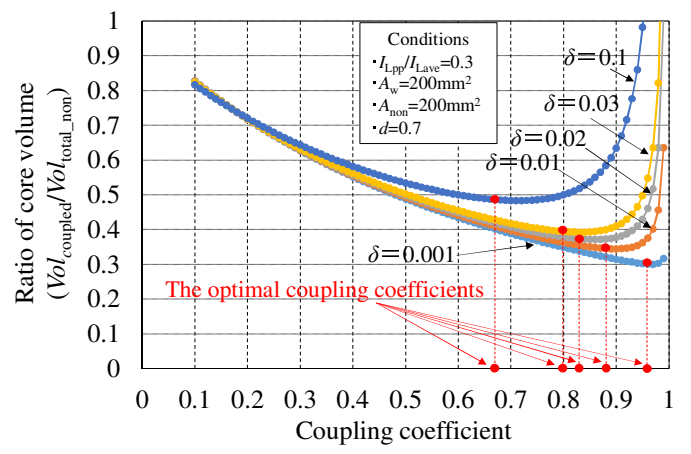

(b) $\quad d$ is fixed as 0.7

Fig. 15. Ratio of core volume of LCI to that of a non-coupled inductor when $k$ is varied.

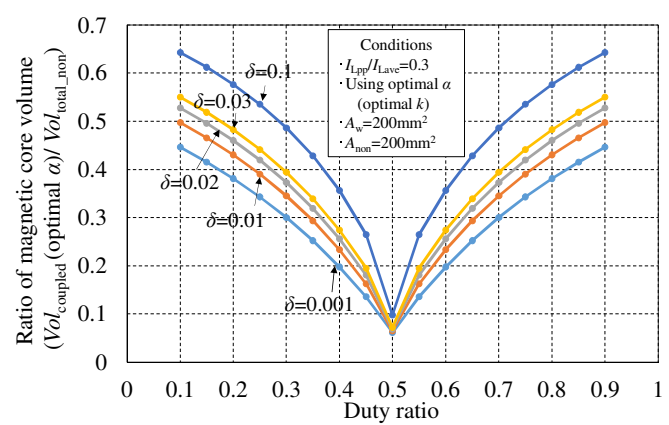

Fig. 16. The downsizing effect of core size with optimal coupling coefficient.

design point with a high downsizing effect. Therefore, the effectiveness of the optimal $k$ is proved. Finally, the downsizing effect of LCI with the optimal $k$ is calculated. Fig. 16 shows the ratio of core volume of LCI with the optimal $k$ to that of noncoupled inductors. As seen in Fig. 16, LCI designed by the optimal $k$ can significantly downsize the core volume while compensating DC-biased magnetization. Even if $\delta=0.1$ and $d$ $=0.1-0.9$, LCI can be downsized by at least $30 \%$ as compared with the total volume of non-coupled inductors.

\section{B. Proposed magnetic design method}

In this section, the magnetic design method for LCI is proposed on the basis of the analysis results. In addition, the effectiveness of LCI designed by the proposed design method is confirmed through this evaluation. The circuit parameters and the magnetic parameters for this evaluation are shown in Tables I and II. The duty ratio of the boost converter is chosen to be 0.583 as a practical value, since the boost converter in the well-
TABLE I CIRCUIT PARAMETERS

\begin{tabular}{lc|c}
\hline \hline Input voltage & $V_{\mathrm{i}}$ & $50 \mathrm{~V}$ \\
\hline Output voltage & $V_{\mathrm{o}}$ & $120 \mathrm{~V}$ \\
\hline Input power & $P_{\mathrm{i}}$ & $1 \mathrm{~kW}$ \\
\hline Duty ratio & $d$ & 0.583 \\
\hline Switching frequency & $f_{\mathrm{s}}$ & $50 \mathrm{kHz}$ \\
\hline Inductor average current & $I_{\mathrm{Lave}}$ & $10 \mathrm{~A}$ \\
\hline $\begin{array}{l}\text { Maximum permissible percentage of } \\
\text { unbalanced inductor average currents }\end{array}$ & $\delta$ & 0.05 \\
\hline Inductor ripple current & $I_{\mathrm{Lpp}}$ & $3 \mathrm{~A}$ \\
\hline Ratio of ripple current & $I_{\mathrm{Lpp}} / I_{\mathrm{Lave}}$ & 0.3 \\
\hline Maximum flux density & $B_{\max }$ & $250 \mathrm{mT}$ \\
\hline Maximum flux & $\Phi_{\max }$ & $46 \mu \mathrm{Wb}$ \\
\hline & & \\
\hline
\end{tabular}

TABLE II

MAGNETIC MATERIAL PROPERTY AND CORE SIZE

\begin{tabular}{lc|c}
\hline \hline Core size & \multicolumn{2}{c}{ EC70 (TDK) } \\
\hline Core material & \multicolumn{2}{c}{ Ferrites $(\mathrm{PC} 40)$} \\
\hline Relative permeability & $\mu_{\mathrm{r}}$ & 2300 \\
\hline Saturation flux density & $B_{\text {sat }\left(100^{\circ} \mathrm{C}\right)}$ & $380 \mathrm{mT}$ \\
\hline Residual magnetic flux density & $B_{\mathrm{r}}$ & $125 \mathrm{mT}$ \\
\hline Sectional area in outer leg & $A_{\mathrm{o}}$ & $184 \mathrm{~mm}^{2}$ \\
\hline Sectional area in central leg & $A_{\mathrm{c}}$ & $211 \mathrm{~mm}^{2}$ \\
\hline Effective magnetic path length & $l_{\mathrm{e}}$ & $144 \mathrm{~mm}$ \\
\hline
\end{tabular}

\footnotetext{
Circuit parameters and magnetic core selection

\begin{tabular}{c}
\hline $\begin{array}{c}\text { Step 1: Decision of ratio of } \\
\text { magnetic reluctance } \alpha\end{array}$ \\
\hline
\end{tabular}
magnetic reluctance $\alpha$

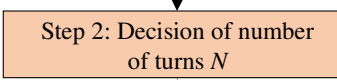
of turns $N$

Step 3: Calculation of magnetic reluctances $R_{\mathrm{mo}}$ and $R_{\mathrm{m}}$

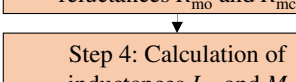
inductances $L_{\mathrm{l}}$ and $M$

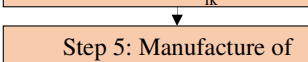
prototype

Fig. 17. The design flowchart of the novel design method considering DC-biased magnetization, caused by little unbalanced currents.
}

known hybrid electric vehicle, Toyota PRIUS ( $2^{\text {nd }}$ ver.), uses this value [36]. The generic magnetic core (material: ferrite (PC40), size: EC70) is selected for the magnetic core of LCI [37]. This core can be obtained easily with no need to custombuild special cores. In this design, the maximum permissible percentage of unbalanced inductor average currents, $\delta$ is assumed within 5\%, considering offset voltages, non-linearity, and temperature dependability of hall-effect current sensors. The gain error of the hall-effect current sensors has to be considered as several percent of the gain error in practical design [38]. In addition, the relationship between the unbalanced current and gain error of the current sensor is shown in Appendix II. The design flowchart of the novel design method is shown in Fig. 17. The contents in each step in the process of the proposed design method are given below:

Step 1: The optimal $\alpha$ and coupling coefficient $k$ are derived. Using (22) in the range of $d>0.5$ and (10), $\alpha$ and $k$ are obtained as 4.98 and 0.83 , respectively.

Step 2: The number of turns in each phase is decided to fulfill the design parameters. As mentioned in section III D, there are two peak fluxes in the outer leg and the central leg in the core. 
Therefore, it is required to investigate which leg in LCI has higher flux density by using the following relation

$$
\frac{B_{\mathrm{op}}}{B_{\mathrm{cp}}}=\frac{\Phi_{\mathrm{o}} / A_{\mathrm{o}}}{\Phi_{\mathrm{c}} / A_{\mathrm{c}}}
$$

where $B_{\mathrm{op}}$ and $B_{\mathrm{cp}}$ are the peak fluxes in the outer leg and the central leg, respectively. By substituting (13) and (14) into (23), $B_{\mathrm{op}} / B_{\mathrm{cp}}$ is calculated as 1.16 . Therefore, the flux density should be regulated at the outer leg. Considering (2) and (13), which comply with the condition of $\Phi_{\mathrm{op}} \leq \Phi_{\mathrm{max}}$, the following equation can be obtained

$$
N_{\mathrm{d}>0.5} \geq \frac{\left\{I_{\text {Lave }} \cdot\left(1+\alpha \cdot \frac{2 d-1}{d}\right) \cdot\left(\delta+\frac{1}{1+2 \alpha}\right)+\frac{1}{2} \cdot I_{\mathrm{Lpp}}\right\} \cdot V_{\mathrm{i}} \cdot d \cdot T_{\mathrm{s}}}{I_{\mathrm{Lpp}} \cdot B_{\max } \cdot A_{\mathrm{o}}}
$$

In this case, the effective range of the number of turns is calculated as $N \geq 20.81$; therefore, $N$ is chosen as 21 turns.

Then, to validate the effectiveness of the optimal $\alpha$ derived in step 1, the number of turns of LCI are compared with that of non-coupled inductors when $\alpha$ is varied. Fig. 18 shows the change trend of the number of turns of LCI and that of the noncoupled inductor. The coupling factor $k$ and the reluctance ratio $\alpha$ are simultaneously shown on the horizontal axis, according to (10). It is clear that there is an optimum value of the coupling factor where the number of turns can be minimized in the LCI configuration. In addition, this optimal coupling coefficient can be derived in Step 1. Other than the optimum value point on the curve, we have two conditions:

- When the coupling factor is higher than the optimum value: the number of turns increases due to the influence of the DC-biased magnetization, as mentioned earlier in equation (11).

- When the coupling factor is lower than the optimum value: in this case, the number of turns increases as the LCI characteristic becomes similar to the non-coupled inductor (i.e., low value of the coupling factor makes the LCI act as two independent magnetic cores).

In the aforementioned two conditions, the winding volume and conduction losses are expected to increase. On the other hand, the number of turns of the non-coupled inductor is calculated as 50.7 turns on the basis of (15). This value is constant because the coupling coefficient has no influence. Consequently, a reduction of $59 \%$ in the number of turns can be achieved at the optimum value of the coupling factor $(k=0.83)$.

Step 3: The magnetic reluctances $R_{\mathrm{mo}}$ and $R_{\mathrm{mc}}$ in the outer legs and the central leg, respectively, are calculated. The magnetic reluctance $R_{\text {mo }}$ in the outer leg can be calculated from (12) because $N, \alpha$, and the other parameters in (12) have already been decided. In this case, $R_{\mathrm{mo}}$ is calculated as $R_{\mathrm{mo}}=$ $0.93 \mathrm{~A} / \mu \mathrm{Wb}$, and $R_{\mathrm{mc}}$ is also calculated as $4.66 \mathrm{~A} / \mu \mathrm{Wb}$ from $\alpha$ $=R_{\mathrm{mc}} / R_{\mathrm{mo}}$.

Step 4: Design values of each inductance have to be derived by using (9) because the magnetic reluctances cannot be measured directly. As the design value, the leakage inductance $L_{\mathrm{lk}}$ is $43 \mu \mathrm{H}$, and the mutual inductance $M$ is calculated as 213 $\mu \mathrm{H}$.

Step 5: The final step is to build the prototype. Usually, the values of the magnetic reluctances $R_{\mathrm{mo}}$ and $R_{\mathrm{mc}}$ in the prototype

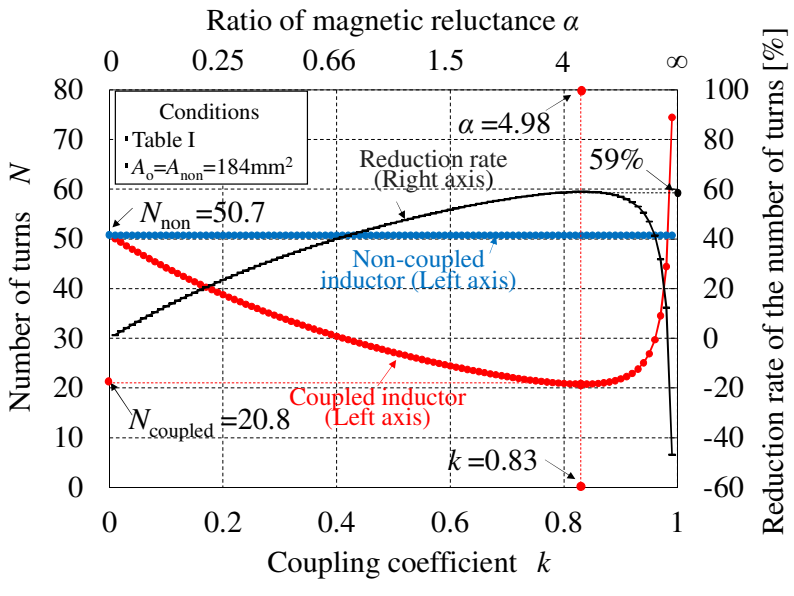

Fig. 18. The change trend of the number of turns of the coupled and noncoupled inductors when $\alpha$ is varied.

are estimated by measuring inductance values $L_{\mathrm{lk}}$ and $M$ because these values cannot be measured directly. This is because the magnetic reluctance value calculated from the geometrical structure has errors caused by the tiny air gaps at the junction of the core, the fringing flux at air gap, and the uneven flow of the magnetic flux in the core. To estimate $R_{\text {mo }}$ values in the prototype, the following relationship is used

$$
R_{\mathrm{mo}}=\frac{N^{2}}{L_{\mathrm{lk}}+2 M}
$$

Equation (25) is derived from (9). By using this relationship, the air gap length of the outer legs is varied by inserting a thin film that has excellent isolation and heat-resisting properties. The value of $R_{\text {mo }}$ can be adjusted to the designed value. As a result, the air gap length in the outer leg is fixed at $0.2 \mathrm{~mm}$. Then, to adjust the magnetic reluctance $R_{\mathrm{mc}}$ in the central leg, the central leg is cut to obtain the designed reluctance value. The air gap length in the central leg is set to $11.3 \mathrm{~mm}$. The prototype of the LCI is shown in Fig. 19. In addition, the designed magnetic parameters and converted magnetic reluctance values from the measured inductances are summarized in Table III. The designed and measured inductance values are also shown in Table IV. There is only a slight error between the designed and measured values, as shown in Tables III and IV. Therefore, the appropriateness of the implementation method is confirmed. Furthermore, to verify the effectiveness of the proposed design method with the optimal $k$ from the perspective of reliability, a prototype based on the conventional design method given in [27] is made. The feature of the conventional design method is that there is no air gap in the outer legs. The advantage of this is that the downsizing effect is higher than the proposed design method. However, if unbalanced currents flow into the windings of the LCI designed by the conventional design method, magnetic saturation can easily occur because the DC-biased magnetization is not considered, and the designed coupling coefficient value is comparatively high. Similarly, the magnetic circuit parameters of LCI based on the conventional design method are shown in Tables V and VI. The conventional LCI is shown in Fig. 20. 
TABLE III

MAGNETIC PARAMTERS (PROPOSED DESIGN)

\begin{tabular}{lc|c}
\hline \hline Winding turn number & $N$ & 21 \\
\hline Magnetic reluctance of the outer leg (designed value) & $R_{\mathrm{mo}}{ }^{*}$ & $0.93 \mathrm{~A} / \mu \mathrm{Wb}$ \\
\hline $\begin{array}{l}\text { Magnetic reluctance of the central leg } \\
\text { (the converted value from measured inductance value) }\end{array}$ & $R_{\mathrm{mo}}$ & $0.91 \mathrm{~A} / \mu \mathrm{Wb}$ \\
\hline Magnetic reluctance of the central leg (designed value) & ${R_{\mathrm{mc}}{ }^{*}}$ & $4.66 \mathrm{~A} / \mu \mathrm{Wb}$ \\
\hline $\begin{array}{l}\text { Magnetic reluctance of the central leg } \\
\text { (the converted value from measured inductance value) }\end{array}$ & $R_{\mathrm{mc}}$ & $4.67 \mathrm{~A} / \mu \mathrm{Wb}$ \\
\hline
\end{tabular}

TABLE IV

INDUCTANCE VALUES (PROPOSED DESIGN)

\begin{tabular}{lc|c}
\hline \hline Mutual inductance (designed value) & $M^{*}$ & $213 \mu \mathrm{H}$ \\
\hline Mutual inductance (measured value) & $M$ & $220 \mu \mathrm{H}$ \\
\hline Leakage inductance (designed value) & $L_{\mathrm{lk}}{ }^{*}$ & $43 \mu \mathrm{H}$ \\
\hline Leakage inductance (measured value of phase 1) & $L_{\mathrm{lk} 1}$ & $43 \mu \mathrm{H}$ \\
\hline Leakage inductance (measured value of phase 2) & $L_{\mathrm{lk} 2}$ & $43 \mu \mathrm{H}$ \\
\hline Coupling coefficient (designed value) & $k^{*}$ & 0.83 \\
\hline Coupling coefficient (measured value) & $k$ & 0.83 \\
\hline
\end{tabular}
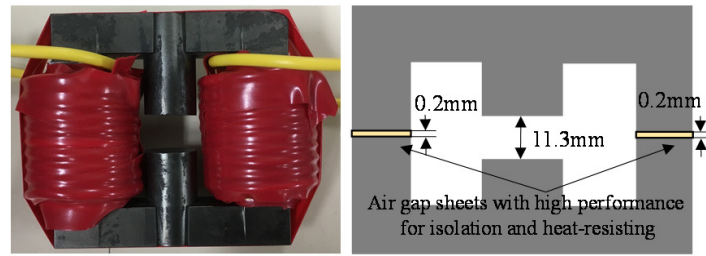

Fig. 19. Prototype of the coupled inductor with air gap in the outer legs (Proposed design method).

\section{CONFIRMATION OF THE VALIDITY OF THE PROPOSED DESIGN METHOD UNDER THE DC-BIASED MAGNETIZATION CONDITION}

\section{A. Simulation results}

In order to show the effectiveness of the proposed design method over the conventional one [27], a multi-phase interleaved boost converter with LCI was simulated. Two simulation case studies are performed using PLECS (Plexim Inc.) simulation software. As a simulation condition, a linear analysis is utilized. In other words, magnetic saturation or variation of the values of the magnetic reluctances depending on magnetic field intensity, is not considered.

- LCI designed by the proposed design method: Fig. 21 (a) shows inductor currents in each phase and magnetic flux waveforms of LCI designed by the proposed design method under conditions specified in Table I. The designed magnetic parameters are $\left(R_{\mathrm{mo}}=0.93 \mathrm{~A} / \mu \mathrm{Wb}, R_{\mathrm{mc}}=\right.$ $4.66 \mathrm{~A} / \mu \mathrm{Wb}, N=21$ turns). As seen in Fig. 21 (a), the inductor currents satisfy both the designed inductor ripple current of $3 \mathrm{~A}$ and inductor average currents with the unbalanced factor $\delta=0.05$. From the magnetic flux waveforms, the peak flux $\Phi_{\mathrm{op} 1}$ in the outer leg is $44.9 \mu \mathrm{Wb}$. The flux density is calculated as $244 \mathrm{mT}$. Therefore, the validity of the proposed method was confirmed.

- LCI designed by the conventional design method [27]: Fig. 21 (b) shows inductor currents in each phase and magnetic flux waveforms under conditions given in Table I using the designed magnetic parameters $\left(R_{\mathrm{mo}}=0.18 \mathrm{~A} / \mu \mathrm{Wb}, R_{\mathrm{mc}}=\right.$ $2.89 \mathrm{~A} / \mu \mathrm{Wb}, N=14$ turns). As seen in Fig. 21 (b), the peak flux $\Phi_{\mathrm{op} 1}$ is much greater than the designed magnetic flux because the conventional design method does not take into account the DC-biased magnetization. The flux density is
TABLE V

MAGNETIC PARAMTERS (CONVENTIONAL DESIGN)

\begin{tabular}{lc|c}
\hline Winding turn number & $N$ & 14 \\
\hline Magnetic reluctance of the outer leg (designed value) & $R_{\mathrm{mo}}{ }^{*}$ & $0.18 \mathrm{~A} / \mu \mathrm{Wb}$ \\
\hline $\begin{array}{l}\text { Magnetic reluctance of the central leg } \\
\text { (the converted value from measured inductance value) }\end{array}$ & $R_{\mathrm{mo}}$ & $0.18 \mathrm{~A} / \mu \mathrm{Wb}$ \\
\hline Magnetic reluctance of the central leg (designed value) & ${R_{\mathrm{mc}}{ }^{*}}$ & $2.89 \mathrm{~A} / \mu \mathrm{Wb}$ \\
\hline $\begin{array}{l}\text { Magnetic reluctance of the central leg } \\
\text { (the converted value from measured inductance value) }\end{array}$ & $R_{\mathrm{mc}}$ & $2.88 \mathrm{~A} / \mu \mathrm{Wb}$ \\
\hline
\end{tabular}

TABLE VI

INDUCTANCE VALUES (CONVENTIONAL DESIGN)

\begin{tabular}{lc|c}
\hline \hline Mutual inductance (designed value) & $M^{*}$ & $523 \mu \mathrm{H}$ \\
\hline Mutual inductance (measured value) & $M$ & $522 \mu \mathrm{H}$ \\
\hline Leakage inductance (designed value) & $L_{\mathrm{lk}}{ }^{*}$ & $34 \mu \mathrm{H}$ \\
\hline Leakage inductance (measured value of phase 1) & $L_{\mathrm{lk} 1}$ & $33 \mu \mathrm{H}$ \\
\hline Leakage inductance (measured value of phase 2) & $L_{\mathrm{lk} 2}$ & $33 \mu \mathrm{H}$ \\
\hline Coupling coefficient (designed value) & $k^{*}$ & 0.94 \\
\hline Coupling coefficient (measured value) & $k$ & 0.94 \\
\hline
\end{tabular}
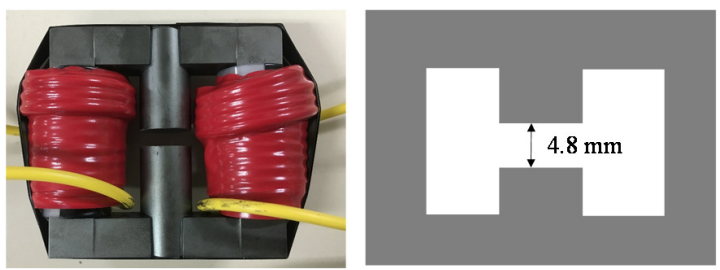

Fig. 20. Prototype of the coupled inductor without air gap in the outer legs (Conventional design method).

calculated as $451 \mathrm{mT}$, which is equal to the saturation value of flux density in the ferrite. Therefore, the reliability of the conventional design method is worse than the proposed design method.

The simulation results agree with the analysis carried out in the previous sections. The proposed design method improves the immunity to the unbalanced inductor currents, and minimizes the effect of DC-biased magnetization, which is not considered in the conventional LCI design method.

\section{B. Experimental results}

In this section, the experimental results are presented. This experimental evaluation is conducted under both balanced $(\delta=$ $0)$ and unbalanced inductor currents $(\delta=0.05)$. The experimental results of the two prototypes are given below:

- LCI designed by the proposed design method: Figs. 22 (a) and (b) show the inductor currents under balanced and unbalanced conditions, respectively. The values of the inductor ripple currents are $2.97 \mathrm{~A}$ and $2.98 \mathrm{~A}$, and they almost agree with the designed value of $3 \mathrm{~A}$. It is clear that the magnetic core has not saturated under both balanced and unbalanced conditions. In the case of magnetic saturation, the inductor ripple current increases significantly as the inductance value decreases. The experimental waveforms show a linear behavior under both current balance $(\delta=0)$ and current unbalance $(\delta=0.05)$ conditions.

- $\quad$ LCI designed by the conventional design method [27]: Figs. 23 (a) and (b) show the inductor currents under balanced and unbalanced conditions, respectively. The values of the inductor ripple currents are $2.98 \mathrm{~A}$, and they almost agree with the designed value of $3 \mathrm{~A}$ under the balanced condition $(\delta=0)$. However, under unbalanced current condition $(\delta=0.05)$, it can be noticed that the 

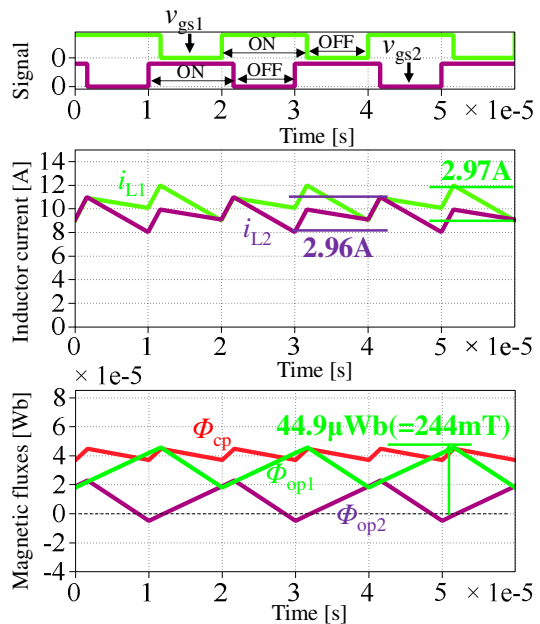

(a) Proposed design method

Fig. 21. Simulation waveforms based on the proposed and conventional design methods under the $\delta=0.05$ condition.

(b) Conventional design method

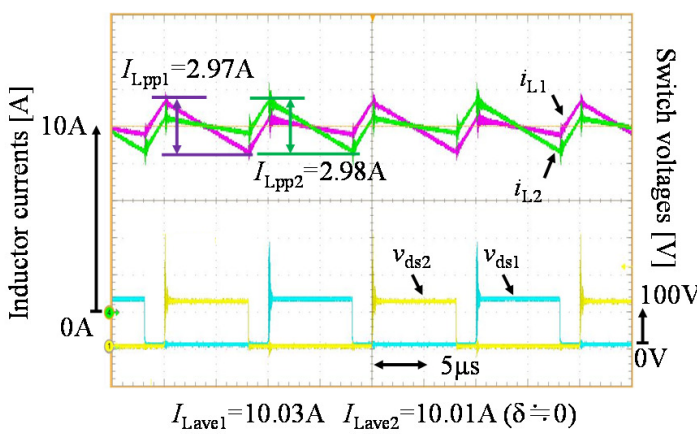

(a) Balanced condition
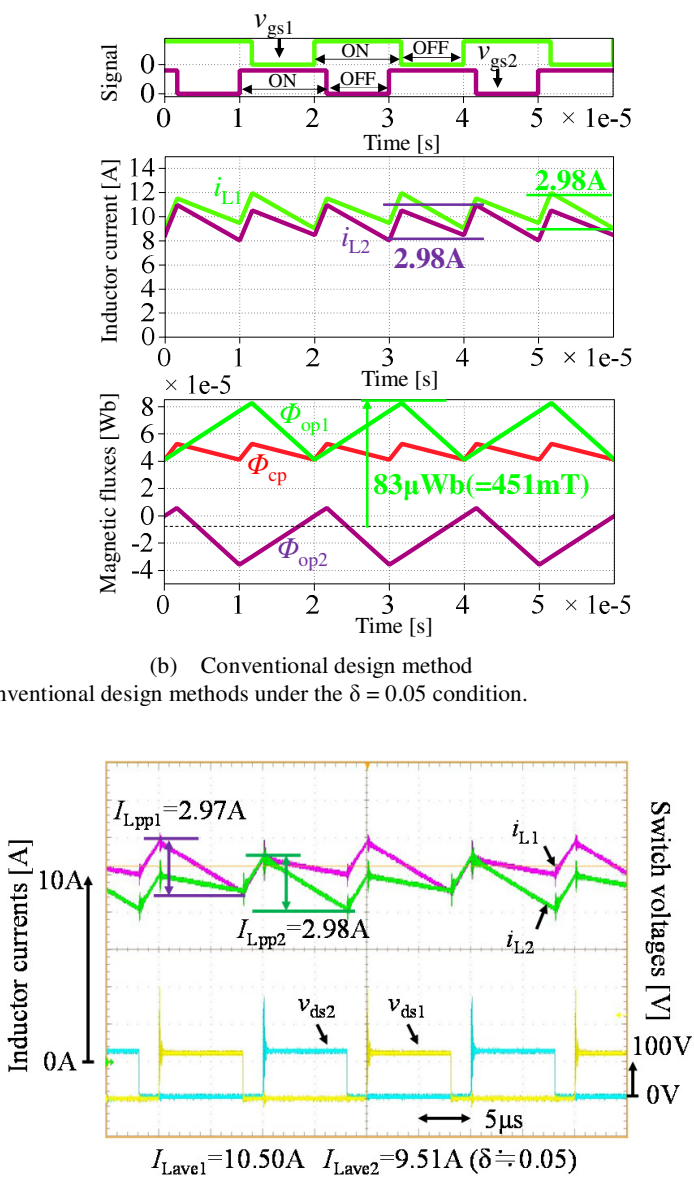

(b) Unbalanced condition

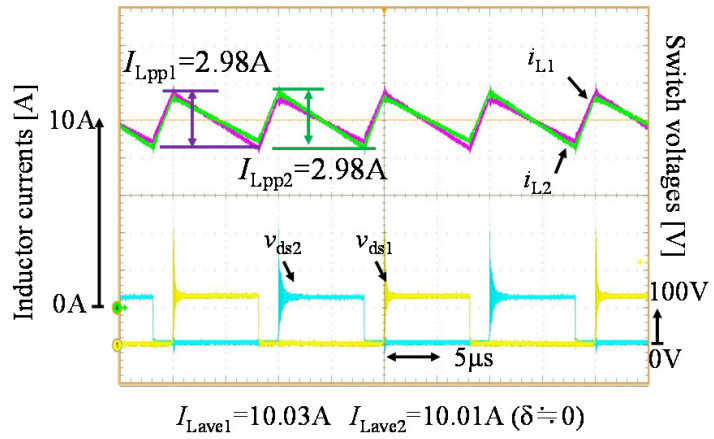

(a) Balanced condition

Fig. 23. Experimental current waveforms of the LCI designed by the conventional design method.

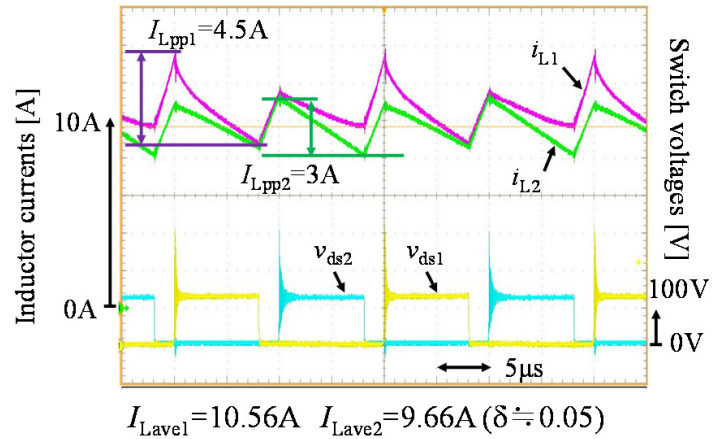

(b) Unbalanced condition magnetic core is saturated. The values of the inductor ripple currents are $4.5 \mathrm{~A}$ and $3 \mathrm{~A}$. This condition occurs because no air gap is inserted in the outer legs, so a high value of the coupling factor helps the DC-biased magnetization to increase leading to core saturation. Therefore, LCI without air gaps in the outer legs or with a lower magnetic reluctance $R_{\mathrm{mo}}$ is required in advanced control schemes such as high precision current sensors for measuring inductor average current.

\section{Evaluation of the proposed design method with optimal coupling coefficient}

Finally, the features of the proposed design method are stated. Table VII summarizes the pros and cons of the proposed design method alongside other inductor design methods. The design examples of core size are also shown in this table to indicate the downsizing effect by using the proposed design method with the optimal value of $k$. From this table, both high immunity to unbalanced current and downsizing magnetic components can be realized by using the proposed design method with the optimal $k$.

\section{CONCLUSION}

This paper proposed a magnetic design method of integrating magnetic components to overcome the magnetic saturation that 
TABLE VII

FEATURES OF EACH DESIGN METHOD AND CORE VOLUME COMPARISON

\begin{tabular}{|c|c|c|c|c|}
\hline & \multicolumn{3}{|c|}{ Loosely Coupled Inductor (LCI) } & \multirow[b]{2}{*}{ Non-coupled inductors } \\
\hline & $\begin{array}{l}\text { Proposed design method } \\
\text { with the optimal } k\end{array}$ & $\begin{array}{l}\text { Proposed design method } \\
\text { with the lower or higher } k \text { than } \\
\text { the optimal } k\end{array}$ & $\begin{array}{l}\text { Conventional design method } \\
\text { without air gap in outer leg[27] }\end{array}$ & \\
\hline Immunity to unbalanced currents & High & High & Very low & Not applicable \\
\hline Core or winding volumes & Small & Large & Very small & Very large \\
\hline \multicolumn{5}{|c|}{ Core volume comparison results } \\
\hline Evaluation conditions & \multicolumn{4}{|c|}{ TABLE I (Note that only duty ratio is changed from 0.583 to 0.75 to confirm the effectiveness of the optimal $k$ ), TABLE II } \\
\hline Number of turns & \multicolumn{4}{|c|}{$N$ : 30turns (each phase) } \\
\hline Winding area & \multicolumn{4}{|c|}{$A_{\mathrm{w}}: 126 \mathrm{~mm}^{2}$} \\
\hline Magnetic reluctance values & $\begin{array}{c}R_{\mathrm{mo}}: 1.30 \mathrm{~A} / \mu \mathrm{Wb} \\
R_{\mathrm{mc}}: 3.45 \mathrm{~A} / \mu \mathrm{Wb} \\
\text { (derived from }(12) \text { ) }\end{array}$ & $\begin{array}{c}R_{\mathrm{mo}}: 0.314 \mathrm{~A} / \mu \mathrm{Wb} \\
R_{\mathrm{mc}}: 4.92 \mathrm{~A} / \mu \mathrm{Wb} \\
\text { (derived from }(12) \text { ) }\end{array}$ & $\begin{array}{l}\qquad R_{\mathrm{mo}}: 0.152 \mathrm{~A} / \mu \mathrm{Wb} \\
R_{\mathrm{mc}}: 5.17 \mathrm{~A} / \mu \mathrm{Wb} \\
\text { (the design method are shown } \\
\text { in }[27] \text { ) }\end{array}$ & $\begin{array}{l}R_{\mathrm{m}}: 3.6 \mathrm{~A} / \mu \mathrm{Wb} \\
\left(R_{\mathrm{m}} \text { is the magnetic }\right. \\
\text { reluctance of the closed } \\
\text { magnetic path in the } \\
\text { core })\end{array}$ \\
\hline Coupling coefficient & $\begin{array}{c}k: 0.73 \\
\text { (the optimal value } \\
\text { derived from (22) and (10)) }\end{array}$ & $\begin{array}{c}k: 0.94 \\
\text { (a provisional value) }\end{array}$ & $\begin{array}{c}k: 0.97 \\
\text { (derived from (10)) }\end{array}$ & Not applicable \\
\hline Inductance values & $\begin{array}{c}L_{\mathrm{lk}}: 110 \mu \mathrm{H} \\
M: 292 \mu \mathrm{H} \\
\text { (derived from (9)) } \\
\end{array}$ & $\begin{array}{c}L_{\mathrm{lk}}: 88 \mu \mathrm{H} \\
M: 1.39 \mathrm{mH} \\
\text { (derived from (9)) }\end{array}$ & $\begin{array}{c}L_{\mathrm{lk}}: 86 \mu \mathrm{H} \\
M: 2.92 \mathrm{mH} \\
\text { (derived from (9)) }\end{array}$ & $L_{\text {self: }}: 250 \mu \mathrm{H}$ \\
\hline Sectional area of the core & $\begin{array}{c}A_{0}: 242 \mathrm{~mm}^{2} \\
A_{\mathrm{c}}: 326 \mathrm{~mm}^{2} \\
\text { (derived from }(24) \text { ) }\end{array}$ & $\begin{array}{c}A_{\mathrm{o}}: 358 \mathrm{~mm}^{2} \\
A_{\mathrm{c}}: 269 \mathrm{~mm}^{2} \\
\text { (derived from (24)) }\end{array}$ & $\begin{array}{c}A_{\mathrm{o}}: 164 \mathrm{~mm}^{2} \\
A_{\mathrm{c}}: 262 \mathrm{~mm}^{2} \\
\text { (the design method are shown } \\
\text { in [27]) }\end{array}$ & $\begin{array}{l}A_{\text {non: }}: 400 \mathrm{~mm}^{2} \\
\text { (derived from (15) and } \\
(2))\end{array}$ \\
\hline Core volume & $\begin{array}{l}\text { Vol }{ }_{\text {coupled: }} 0.045 \text { liter } \\
\text { (derived from (16)) }\end{array}$ & $\begin{array}{l}\text { Vol }{ }_{\text {coupled }}: 0.065 \text { liter } \\
\text { (derived from (16)) }\end{array}$ & $\begin{array}{l}\text { Vol }{ }_{\text {coupled: }} 0.029 \text { liter } \\
\text { (derived from (16)) }\end{array}$ & $\begin{array}{l}\text { Vol } l_{\text {total_non: }} 0.099 \text { liter } \\
\text { (derived from (18)) }\end{array}$ \\
\hline
\end{tabular}

arises from unbalanced inductor currents in interleaved multiphase boost converters. The proposed design method is especially useful for practical designs. We obtain the following information for integrated magnetic components used in interleaved boost converters;

1) On the basis of the analysis results of Section III, when an unbalanced average current flows into the windings of the LCI with a higher coupling coefficient, the peak flux in the outer leg of LCI increases considerably, causing magnetic saturation. When magnetic saturation is avoided in a state where a high coupling coefficient is maintained, the downsizing effect of the LCI is reduced in comparison with non-coupled inductors. However, when the coupling coefficient is optimized based on the maximum permissible percentage of unbalanced inductor average currents, LCI can be downsized. These results are given in Sections IV and V.

2) The design and implementation methods were proposed in Section IV. The validity of the design and implementation methods are confirmed from the simulation and experimental tests in Section V. By using the proposed design method, high immunity to unbalanced inductor current within the range of the designed $\delta$ can be realized, while maintaining the downsizing effect of LCI.

Therefore, this design method can enhance the reliability of integrated magnetic components in interleaved converters. Although the validity of the proposed design method was confirmed by using ferrite cores, the proposed design method is especially effective for high-permeability magnetic materials such as nanocrystalline, amorphous and $\mathrm{Si}$-steel cores.

\section{ACKNOWLEDGMENT}

This work was partially supported by the Japan Society for the Promotion of Science (JSPS) KAKENHI Grant number $16 \mathrm{~K} 18059$.

\section{APPENDIX}

\section{ANALYSIS OF INDUCTOR RIPPLE CURRENTS}

In this section, the current ripple analysis is conducted to clarify the relationship between each inductance and inductor ripple current. Figs. 24 (a) and (b) illustrate the inductor current waveforms for duty ratio less and greater than 0.5 , respectively. Note that these waveforms are drawn under the balanced inductor average current condition. In the two-phase interleaved boost converter, there are four operation modes and these operation modes differ for duty ratio less and greater than 0.5 . The relationships between the applied voltages to the inductor windings and inductor ripple currents of each phase are given by:

$$
v_{\mathrm{L} 1}=L_{\text {self }} \frac{i_{\mathrm{L} 1}}{d t}-M \frac{d i_{\mathrm{L} 2}}{d t}, \quad v_{\mathrm{L} 2}=L_{\text {self }} \frac{i_{\mathrm{L} 2}}{d t}-M \frac{d i_{\mathrm{L} 1}}{d t}
$$

where $v_{\mathrm{L} 1}$ and $v_{\mathrm{L} 2}$ are the applied voltages to inductor windings in each phase, and $v_{\mathrm{L} 1}$ and $v_{\mathrm{L} 2}$ equal $V_{\mathrm{i}}$ under the on-state condition, and equal $V_{\mathrm{i}}-V_{\mathrm{o}}$ under the off-state condition. The current ripple analysis results for each operation modes are summarized in Table VII. As seen in Table VII, the inductor currents $i_{\mathrm{L} 1}, i_{\mathrm{L} 2}$ can be separated into a common current $i_{\text {com }}$ and a wheeling current $i_{\mathrm{wh}}$, and their current paths are shown in Fig. 25 . The inductor ripple current equations including both the common and wheeling current components are summarized in Table IX. The slope of $i_{\text {com }}$ changes every time the operation mode changes. Based on (31) and (33), the leakage inductance $L_{\mathrm{lk}}=L_{\text {self }}-M$ decides the amplitude of common ripple current. On the other hand, the slope of $i_{\mathrm{wh}}$ changes only during modes 1 and 2 because no voltage is applied to the transformer of LCI during modes 3 and 4 . If the value of mutual inductance is high, the wheeling ripple current decreases dramatically. In the case of the non-coupled inductor, the inductor ripple current usually increases as long as the switch $S_{1}$ is turned on. On the other 


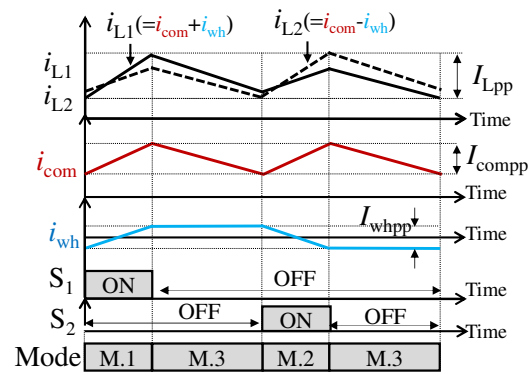

(a) $d \leq 0.5$

Fig. 24. Inductor current waveforms for duty ratio less or greater than 0.5 .

(b) $d>0.5$

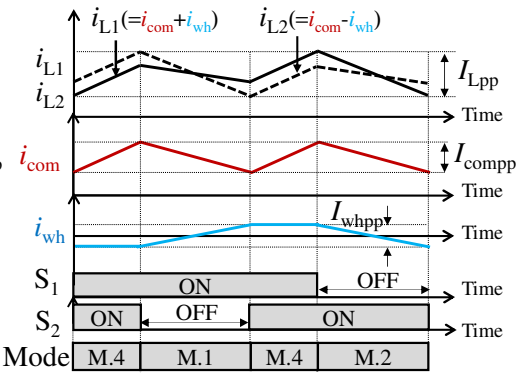

TABLE VIII

ANALYSIS RESULTS OF THE RELATIONSHIP BETWEEN EACH INDUCTANCE AND INDUCTOR CURRENT

\begin{tabular}{|c|c|c|c|}
\hline Mode1 $\left(\mathrm{S}_{1}: \mathrm{ON}, \mathrm{S}_{2}:\right.$ OFF $)$ & & $\operatorname{Mode} 2\left(\mathrm{~S}_{1}: \mathrm{OFF}, \mathrm{S}_{2}: \mathrm{ON}\right)$ & \\
\hline$\left\{\begin{array}{l}\frac{d i_{\mathrm{L} 1 \text { modl } 1}}{d t}=\frac{1}{\left(L_{\text {self }}-M\right)} \cdot\left(V_{\mathrm{i}}-\frac{1}{2} V_{\mathrm{o}}\right)+\frac{1}{\left(L_{\text {self }}+M\right)} \cdot \frac{1}{2} V_{\mathrm{o}} \\
\frac{d i_{\mathrm{L} 2 \_ \text {mod } 1}}{d t}=\frac{1}{\left(L_{\text {self }}-M\right)} \cdot\left(V_{\mathrm{i}}-\frac{1}{2} V_{\mathrm{o}}\right)-\frac{1}{\left(L_{\text {self }}+M\right)} \cdot \frac{1}{2} V_{\mathrm{o}}\end{array}\right.$ & (27) & $\begin{array}{l}\frac{d i_{\mathrm{L} 1 \_ \text {mod } 2}}{d t}=\frac{1}{\left(L_{\text {self }}-M\right)} \cdot\left(V_{\mathrm{i}}-\frac{1}{2} V_{\mathrm{o}}\right)-\frac{1}{\left(L_{\text {self }}+M\right)} \cdot \frac{1}{2} V_{\mathrm{o}} \\
\frac{d i_{\mathrm{L} 2 \text { mod } 2}}{d t}=\frac{1}{\left(L_{\mathrm{self}}-M\right)} \cdot\left(V_{\mathrm{i}}-\frac{1}{2} V_{\mathrm{o}}\right)+\frac{1}{\left(L_{\mathrm{self}}+M\right)} \cdot \frac{1}{2} V_{\mathrm{o}}\end{array}$ & $(28)$ \\
\hline Mode3 $\left(\mathrm{S}_{1}\right.$ : OFF, $\mathrm{S}_{2}$ : OFF) & & Mode4 $\left(\mathrm{S}_{1}: \mathrm{ON}, \mathrm{S}_{2}: \mathrm{ON}\right)$ & \\
\hline$\frac{d i_{\mathrm{L} 1 \_\bmod 3}}{d t}=\frac{d i_{\mathrm{L} 2 \_\bmod 3}}{d t}=\frac{1}{\left(L_{\mathrm{self}}-M\right)} \cdot\left(V_{\mathrm{i}}-V_{\mathrm{o}}\right)$ & (29) & $\frac{d i_{\mathrm{L} 1 \_\bmod 4}}{d t}=\frac{d i_{\mathrm{L} 2 \_\bmod 4}}{d t}=\frac{1}{\left(L_{\mathrm{self}}-M\right)} \cdot V_{\mathrm{i}}$ & (30) \\
\hline
\end{tabular}

TABLE IX

INDUCTOR RIPPLE CURRENT EQUATIONS INCLUDING ITS CURRENT COMPONETS

\begin{tabular}{|c|cc|cc|c|}
\hline Duty ratio & \multicolumn{3}{|c|}{ Common ripple current } & Wheeling ripple current & Inductor current ripple \\
\hline$d \leq 0.5$ & $I_{\text {compp }}=\frac{1}{L_{\text {self }}-M} \cdot\left(V_{\mathrm{i}}-\frac{V_{\mathrm{o}}}{2}\right) \cdot d \cdot T_{\mathrm{s}}$ & $(31)$ & $I_{\mathrm{whpp}}=\frac{1}{L_{\text {self }}+M} \cdot \frac{V_{\mathrm{o}}}{2} \cdot d \cdot T_{\mathrm{s}}$ & $(32)$ \\
\hline$d>0.5$ & $I_{\text {compp }}=\frac{1}{L_{\text {self }}-M} \cdot\left(\frac{V_{\mathrm{o}}}{2}-V_{\mathrm{i}}\right) \cdot(1-d) \cdot T_{\mathrm{s}}$ & $(33)$ & $I_{\mathrm{whpp}}=\frac{1}{L_{\mathrm{self}}+M} \cdot \frac{V_{\mathrm{o}}}{2} \cdot(1-d) \cdot T_{\mathrm{s}}$ & $(34)$ & $(35)$ \\
\hline
\end{tabular}

hand, if LCI has high mutual inductance, the inductor ripple current of LCI decreases even if the switch S1 is turned on. Therefore, in the case of the LCI, the inductor ripples can be effectively reduced in comparison with the non-coupled inductor, which is considered as one of the advantages of the employing integrated magnetics.

If a positively coupled inductor with $+M$ (not $-M$ ) is used, although the common ripple current can be reduced effectively, the wheeling ripple current is increased. In addition, the DC flux cancellation would not be obtained in this case, because the DC fluxes generated by each phase average current are added together on the transformer magnetic path.

\section{RELATIONSHIP BETWEEN THE UNBALANCED INDUCTOR CURRENT AND UNBALANCED CURRENT SENSOR GAINS}

This section introduces the relationship between the gain errors of the current sensors in each phase and the unbalanced average currents. The interleaved converter usually employs a current balancing control. One of the examples of current balancing control is shown in Fig. 26. In this control block, the output voltage feedback loop is omitted for simplicity, and it is shown as open loop control. This current balancing control has a PI compensator with a long integrating time as compared with the switching period of $S_{1}$ and $S_{2}$ in order to eliminate the influence of inductor ripple currents. Then, the output signal of the PI compensator, which shows an integrated difference between the inductor average current in each phase, is the input to the voltage control signal through the adder or subtractor. In other words, by slightly modulating the pulse width of PWM signals in each phase, the inductor average currents in each phase are balanced. Then, in order to investigate this relationship, a simulated evaluation is conducted. The circuit parameters for evaluation are the same as Table I. The current sensor gains in each phase are $K_{1}=0.095$ and $K_{2}=0.105$, respectively. These values have a tolerance (or an error) of $\delta=$ $\pm 5 \%$ from the average gain $K_{\text {ave }}\left(=\left(K_{1}+K_{2}\right) / 2\right)$, and the relationship is shown as follows:

$$
\left\{\begin{array}{l}
K_{1}=K_{\text {ave }}(1 \mp \delta) \\
K_{2}=K_{\text {ad }}(1+\delta)
\end{array}\right.
$$

The reference voltage $V_{\text {ref }}$ is set as 0.583 , and the peak-topeak amplitude of the saw tooth voltage is $1 \mathrm{~V}$. On the other hand, the transfer function of PI compensator is as follows:

$$
G_{\mathrm{PI}}(\mathrm{s})=K_{\mathrm{p}}+\frac{K_{\mathrm{p}}}{s T_{\mathrm{i}}}
$$

where $K_{\mathrm{p}}$ is the proportional gain and $T_{\mathrm{i}}$ is the integrating time. In this simulation, $K_{\mathrm{p}}$ and $T_{\mathrm{i}}$ are set at 0.001 and $100 \mu \mathrm{s}$, respectively, as five times the switching period. The magnetic parameters of $\mathrm{LCI}$ are used in the design values shown in Table III. By using these conditions, the simulated evaluation was carried out. The inductor current waveforms are shown in Fig. 27. From this figure, the unbalanced ratio of the inductor average current to complete balanced condition is identical to 
the unbalanced gains of current sensors. Therefore, the gain errors of the current sensors in each phase and the unbalanced average currents are summarized as follows:

$$
\begin{aligned}
& I_{\text {Lave1 }}=\frac{K_{2}}{K_{\text {ave }}}=\frac{K_{\text {ave }}(1 \pm \delta)}{K_{\text {ave }}}=1 \pm \delta \\
& I_{\text {Lave2 }}=\frac{K_{1}}{K_{\text {ave }}}=\frac{K_{\text {ave }}(1 \mp \delta)}{K_{\text {ave }}}=1 \mp \delta
\end{aligned}
$$

These relationships are helpful in deciding the maximum permissible percentage of the practical design of LCI as a reference.

\section{REFERENCES}

[1] M. Kuypers, "Application of 48 Volt for Mild Hybrid Vehicles and High Power Loads", SAE Technical Paper, Apr. 2014, 8 pages.

[2] Y. Hasuke, H. Sekine, K. Katano and Y. Nonobe, "Development of Boost Converter for MIRAI", SAE Technical Paper, Apr. 2015, 6 pages.

[3] M. Hirakawa, M. Nagano, Y. Watanabe, K. Andoh, S. Nakatomi and S. Hashino, "High Power Density DC/DC Converter using the CloseCoupled Inductors", in Proc. IEEE Energy Conver. Cong. and Expo. (ECCE), Sep. 2009, pp. 1760-1767.

[4] M. Pavlovsky', G. Guidi, and Atsuo Kawamura, "Assessment of Coupled and Independent Phase Designs of Interleaved Multiphase Buck/Boost DC-DC Converter for EV Power Train”, IEEE Trans. on Power Electron., Vol. 29, No. 6, pp. 2693-2704, Jun. 2014.

[5] K. J. Hartnett, J. G. Hayes, M. G. Egan and M. S. Rylko, "CCTT-Core Split-Winding Integrated Magnetic for High-power DC-DC Converters", IEEE Trans. on Power Electron., Vol. 28. Nov. 2013. pp. 4970-4984,

[6] E. A. Burton, G. Schrom, F. Paillet, J. Douglas, W. J. Lambert, K Radhakrishnan and M. J. Hill, "FIVR - Fully Integrated Voltage Regulators on 4th Generation Intel ${ }^{\circledR}$ Core ${ }^{\mathrm{TM}}$ SoCs", in Proc. IEEE Applied Power Electron. Conf. and Expo. (APEC), Mar. 2014, pp 432439.

[7] Q. Li, Y. Dong, F. C. Lee, and D. J. Gilham, "High-Density Low-Profile Coupled Inductor Design for Integrated Point-of-Load Converters", IEEE Trans. on Power Electron., Vol. 28, No. 1, pp. 547-554. Jan. 2012.

[8] J. Imaoka, S. Kimura, Y. Itoh, W. Martinez, M. Yamamoto, M. Suzuki, and K. Kawano, "Feasible Evaluations of Coupled Multilayered Chip Inductor for POL Converters", IEEJ J. of Ind. App., Vol. 4, No. 3, pp. 126135. May. 2015

[9] K. J. Hartnett, J. G. Hayes, M. G. Egan, M.S. Rylko, B. J. Barry and J. W Masłon, "Comparison of $8-\mathrm{kW}$ CCTT IM and Discrete Inductor Interleaved Boost Converter for Renewable Energy Applications", IEEE Trans. on Ind. App., Vol. 51, No. 3, pp.2455-2469, May. 2015.

[10] K. Tseng and C. Huang, "High Step-Up High-Efficiency Interleaved Converter with Voltage Multiplier Module for Renewable Energy System", IEEE Trans. on Ind. Ele., Vol. 61, No. 3, pp. 1311-1319. Mar 2014.

[11] L. Meyer, B. Bras, "Rare earth metal recycling", in Proc. IEEE Int. symposium on sustainable systems and technology (ISSST), May. 2011. pp. 1-6,

[12] L. Gaines, "The future of automotive lithium-ion battery recycling: Charting a sustainable course", Sustainable Materials and Technologies, Vol. 1-2, pp. 2-7, Dec. 2014

[13] National Institute for Materials Science, "The wall of resource constraints worldwide by 2050", [Online]. Available: http://www.nims go.jp/news/press/ 2007/02/200702150/p200702150.pdf (in Japanese)

[14] J. W. Kolar, J Biela and J. Miniböck, "Exploring the Pareto Front of Multi-Objective Single-Phase PFC Rectifier Design Optimization -99.2\% Efficiency vs. 7kW/dm3 Power Density", in Proc. IEEE 6th International Power Electron. and Motion Control Conf., (IPEMC) May. 2009. pp. 121

[15] J. Imaoka, M. Yamamoto, Y. Nakamura, T. Kawashima, "Analysis of Output Capacitor Voltage Ripple in Multi-Phase Transformer-Linked Boost Chopper Circuit", IEEJ J. of Ind. App., Vol. 2 No. 5 pp. 252-260. Sep. 2013.

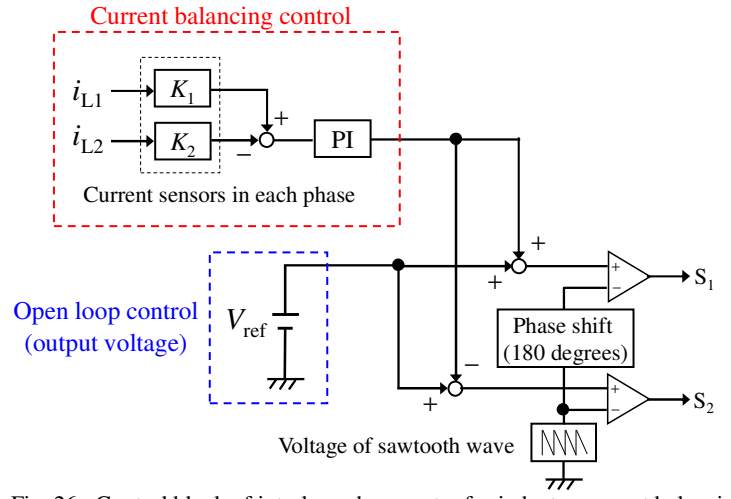

Fig. 26. Control block of interleaved converter for inductor current balancing control.

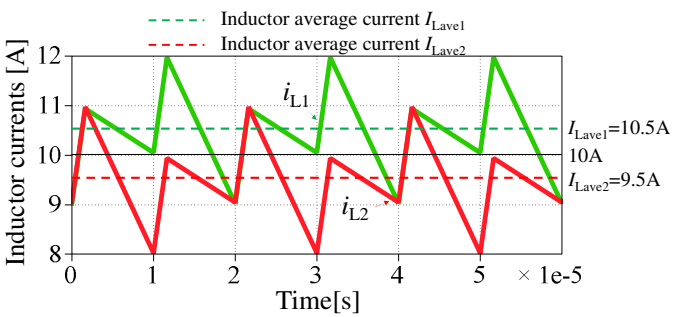

Fig. 27. Inductor current waveforms.

[16] P. Zumel, O. Garc'1a, J. A. Oliver' and J. A. Cobos', "Differential-Mode EMI Reduction in a Multiphase DCM Flyback Converter", IEEE Trans. on Power Electorn., Vol. 24, No. 8, pp. 2013-2020. Aug. 2009.

[17] K. Mainali, and R. Oruganti, "Conducted EMI Mitigation Techniques for Switch-Mode Power Converters: A Survey", IEEE Trans. on Power Electron., Vol. 25, No. 9, pp. 2344-2356. Sep. 2010.

[18] C. Wang, M. Xu, F. C. Lee, and B. Lu, "EMI Study for the Interleaved Multi-Channel PFC", in Proc. IEEE Power Electron. Specialists Conf. (PESC), Jul. 2007. pp. 1336-1342.

[19] T. Qian and B. Lehman, "Coupled Input-Series and Output-Parallel Dual Interleaved Flyback Converter for High Input Voltage Application”, IEEE Trans. on Power Electron., Vol. 23, No. 1, pp. 88-95. Feb. 2008.

[20] F. Forest, E. Labouré, T. A. Meynard and J. Huselstein, "Multicell Interleaved Flyback Using Intercell Transformers", IEEE Trans. on Power Electron., Vol. 22, No. 5, pp. 1662-1671. Sep. 2007.

[21] L. Wong, Y. Lee, D. K. Cheng, and M. H. L. Chow, "Two-Phase Forward Converter using an Integrated Magnetic Component", IEEE Trans. on Aerospace and Electron. Sys., Vol. 40, No.4, pp.1294-1310 Sep. 2004.

[22] Y. Su, D. Hou, F. C. Lee and Q. Li, "Low Profile Coupled Inductor Substrate with Fast Transient Response", in Proc. of IEEE Applied Power Electron. Conf. and Expo., (APEC), Mar. 2015. pp. 1161-1168.

[23] P-L Wong, F. C. Lee, P. Xu, K. Yao, "Critical Inductance in Voltage Regulator Modules”, IEEE Trans. on Power Electron., Vol. 17, No. 4, pp. 485-492. Aug. 2002.

[24] P. Wong, P. Xu, B. Yang and F. C. Lee, "Performance Improvements of Interleaving VRMs with Coupling Inductors", IEEE Trans. on Power Electron., Vol. 16, No.4, pp.499-507. Jul. 2001.

[25] W. Huang, and B. Lehman, "A Compact Coupled Inductor for Interleaved Multiphase DC-DC Converters", IEEE Trans. on Power Electron., Vol. 31, No. 10, pp. 6770-6775, Oct. 2016

[26] J. Imaoka, S. Kimura, W. Martinez and M. Yamamoto, "A Novel Integrated Magnetic Core Structure Suitable for Transformer-Linked Interleaved Boost Chopper Circuit", IEEJ J. of Ind. App., Vol. 3, No. 5, pp.395-404, Sep. 2014.

[27] S. Kimura, Y. Itoh, W. Martinez, M. Yamamoto, and J. Imaoka, "Downsizing Effects of Integrated Magnetic Components in High Power Density DC-DC Converters for EV and HEV Applications", IEEE Trans. on Ind. App., Vol. 52, No. 4, pp. 3294-3305. Jul. 2016

[28] H. Kosai, S. McNeal, B. Jordan, J. Scofield, B. Ray, and Z.Turgut, "Coupled Inductor Characterization for a High Performance Interleaved 
Boost Converter", IEEE Trans. on Magnetics, Vol. 45, No. 10, pp. 48124815. Oct. 2009.

[29] K. Umetani, J. Imaoka, M. Yamamoto, S. Arimura, and T. Hirano, "Evaluation of the Lagrangian Method for Deriving Equivalent Circuits of Integrated Magnetic Components: A Case Study Using the Integrated Winding Coupled Inductor", IEEE Trans. on Ind. App., Vol. 51, No. 1, pp. 547-555. Jun. 2015.

[30] W. Huang and J. A. A. Qahouq, "Input Voltage Ripple-Based Sensorless Current Sharing Autotuning Controller for Multiphase DC-DC Converters", IEEE Trans. on Ind. App., Vol. 52, No. 5, pp. 4117-4125. Sep. 2016.

[31] H. Kim, M. Falahi, T. M. Jahns, and M. W. Degner, "Inductor Current Measurement and Regulation Using a Single DC Link Current Sensor for Interleaved DC-DC Converters", IEEE Trans. on Power Electron., Vol. 26, No. 5, pp. 1503-1510. May. 2011.

[32] H-C. Chen, C-Y Lu, and L-M Huang, "Decoupled Current-Balancing Control With Single-Sensor Sampling-Current Strategy for Two-Phase Interleaved Boost-Type Converters", IEEE Trans. on Ind. Ele., Vol. 63, No. 3, pp. 1507-1518. Mar. 2016.

[33] M. Gleissner, Mark-M. Bakran, "Influence of Inverse Coupled Inductors on Fault-Tolerant Operation of Two-Phase DC-DC Converters", in Proc. 13th European Conference on Power Ele. and App., (EPE), Sep. 2015. pp. 1-11.

[34] Y. Itoh, F. Hattori, S. Kimura, J. Imaoka, M. Yamamoto, "Design method considering magnetic saturation issue of coupled inductor in interleaved CCM boost PFC converter", in Proc. IEEE Energy Conver. Cong. and Expo. (ECCE), Sep. 2015. pp. 2616-2621.

[35] W. Colonel and T. McLyman, Transformer and Inductor Design Handbook. New York, NY, USA: Marcel Dekker, 2004.

[36] M. Olszewski, "EVALUATION OF THE 2010 TOYOTA PRIUS HYBRID SYNERGY DRIVE SYSTEM", Report of Oak Ridge National Laboratory, Mar. 2011. [Online]. Available: http://info.ornl.gov/sites/publications/files/pub26762.pdf

[37] [Online]. Available: https://product.tdk.com/info/en/404.html

[38] [Online]. Available: http://www.lem.com/hq/en/content/view/28/104/

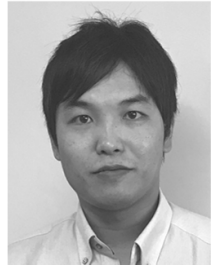

supply.
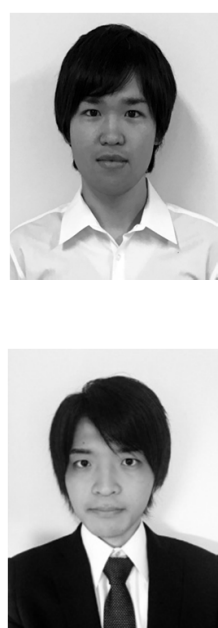

Jun Imaoka (S'11-M'15) received his M.S. and Ph. D degrees in electronic function and system engineering from Shimane University in 2013 and 2015 respectively. Since Oct. 2015, he has been with Kyushu University as an Assistant Professor, Fukuoka, Japan. His research interests include design of integrated magnetic components, modeling for high power density power converters, thermal management for power converters, magnetic material application, EMI of switching power

Kenkichiro Okamoto received B.S. degree in electrical and electronic engineering from Yamaguchi University, Yamaguchi, Japan, in 2016. He is currently M. S. degree at the electrical engineering, Kyushu University, Fukuoka, Japan. His current research interests include design of magnetic components for DC/DC converter.

Shota Kimura (S'13) received his B.S. and M.S. degree electrical and electronic system engineering from Shimane University, Shimane, Japan, in 2013 and 2015 respectively. Since 2015 , He is currently working toward a Ph.D. degree in mechanical/electronic engineering and information systems at Shimane University, Shimane, Japan. His research interests include design of integrated magnetic components for high power density DC-DC converter.

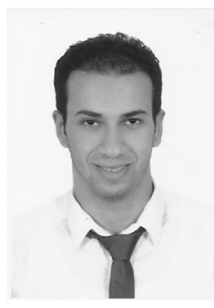

Mostafa Noah (S'15) received his B.Sc. and M.Sc. degrees in Electrical Engineering from Cairo University, Egypt in 2009 and 2014. He is currently pursuing the Ph.D. degree at Shimane University, Japan. He also was with multinational consultant Dar Al-Handasah and SCG as an Electrical design engineer from 2009-2015, where he was responsible of the designing the Electrical system for mega projects. His current research interests include DC/DC converters, design of integrated magnetics, and transformer design for LLC resonant converter.

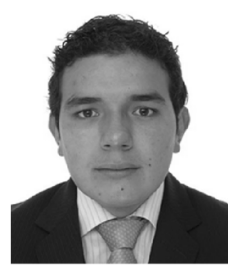

Wilmar Martinez (S'9-M'16) received B.S. degree in electronics engineering and the M.Sc. degree in electrical engineering from Universidad Nacional de Colombia in 2011 and 2013, and the Ph.D. degree in electronic function and system engineering from Shimane University, Japan in 2016. He is currently with the Toyota Technological Institute, Japan. His current research interests include multi objective optimization of power converters, evaluation of iron losses at high carrier frequency in electric motors, and high power density converters for Electric Vehicles and Renewable Energies.

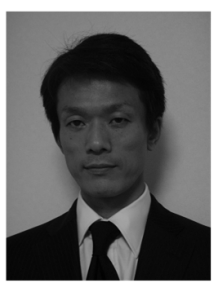

Masayoshi Yamamoto (M'11) received his M.S. and $\mathrm{Ph} . \mathrm{D}$. degree in science and engineering from Yamaguchi University, Yamaguchi, Japan in 2000 and 2004 respectively. From 2004 to 2005, he was with Sanken Electric Co., Ltd., Saitama, Japan. From 2006 to 2017, he was with the Interdisciplinary Faculty of Science and Engineering in Shimane University, Japan, as an Associate Professor. He is currently a Professor at Institute of Materials and Systems for Sustainability (IMaSS), Nagoya University, Japan. His research interests include power supply for HEV (boost converter, buck converter, 3-phase inverter, digital control), charging system for EV, LED illumination system for a tunnel, EMI of switching power supply, and wireless power transfer.

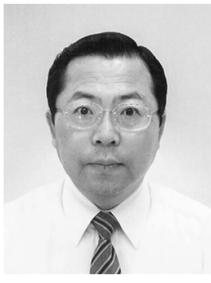

Masahito Shoyama (M'93-SM'06) received his B. S. in Electrical Engineering and his Dr. Eng. from Kyushu University, Fukuoka, Japan, in 1981 and 1986, respectively. He joined the Dept. of Electronics, Kyushu University as a Research Associate in 1986. He had been an Associate Professor since 1990, and he has been a Professor since 2010

Since 2009 he has been with the Dept. of Electrical Engineering, Faculty of Information Science and Electrical Engineering, Kyushu University. He has been active in the field of power electronics, especially in the areas of bi-directional converters for DC/AC power systems, high-frequency switching converters for renewable energy sources, power factor correction (PFC) converters, and electromagnetic compatibility (EMC). 